\title{
Developing high strength and ductility in biomedical Co-Cr cast alloys by simultaneous doping with nitrogen and carbon
}

Kenta Yamanaka ${ }^{\mathrm{a},}{ }^{,}$, Manami Mori ${ }^{\mathrm{b}}$, Akihiko Chiba ${ }^{\mathrm{a}}$

${ }^{a}$ Institute for Materials Research, Tohoku University, 2-1-1 Katahira, Aoba-ku, Sendai 980-8577, Japan

${ }^{\mathrm{b}}$ Department of Materials and Environmental Engineering, National Institute of Technology, Sendai College, 48 Nodayama, Medeshima-Shiote, Natori 981-1239, Japan

*Corresponding author: Kenta Yamanaka

Tel.: +81222152118

Fax: +81222152116

E-mail address: k_yamanaka@imr.tohoku.ac.jp (K. Yamanaka)

\section{ABSTRACT}

There is a strong demand for biomedical $\mathrm{Co}-\mathrm{Cr}$-based cast alloys with enhanced mechanical properties for use in dental applications. We present a design strategy for development of $\mathrm{Co}-\mathrm{Cr}-\mathrm{W}$-based cast alloys with very high strength, comparable to that of wrought $\mathrm{Co}-\mathrm{Cr}$ alloys, without loss of ductility. The strategy consists of simultaneous doping of nitrogen and carbon, accompanied by increasing of the $\mathrm{Cr}$ content to increase the nitrogen solubility. The strategy was verified by preparing $\mathrm{Co}-33 \mathrm{Cr}-9 \mathrm{~W}-0.35 \mathrm{~N}-(0.01-0.31) \mathrm{C}$ (mass\%) alloys. We determined the carbon concentration dependence of the microstructures and their mechanical properties. Metal ion release of the alloys in an aqueous solution of $0.6 \%$ sodium chloride 
$(\mathrm{NaCl})$ and $1 \%$ lactic acid was also evaluated to ensure their corrosion resistance. As a result of the nitrogen doping, the formation of a brittle $\sigma$-phase, a chromium-rich intermetallic compound, was significantly suppressed. Adding carbon to the alloys resulted in finer-grained microstructures and carbide precipitation; accordingly, the strength increased with increasing carbon concentration. The tensile ductility, on the other hand, increased with increasing carbon concentration only up to a point, reaching a maximum at a carbon concentration of $\sim 0.1$ mass $\%$ and decreasing with further carbon doping. However, the alloy with 0.31 mass $\%$ of carbon exhibited $14 \%$ elongation and also possessed very high strength $(725 \mathrm{MPa}$ in $0.2 \%$ proof stress). The addition of carbon did not significantly degrade the corrosion resistance. The results show that our strategy realizes a novel high-strength $\mathrm{Co}-\mathrm{Cr}$-based cast alloy that can be produced for advanced dental applications using a conventional casting procedure. Keywords: biomedical Co-Cr alloy; alloy design; solidification microstructures; mechanical properties; corrosion resistance

\section{Introduction}

Owing to their excellent mechanical properties as well as excellent corrosion and wear resistance, $\mathrm{Co}-\mathrm{Cr}$-based alloys have been extensively used in biomedical applications that involve exposure to severe in vivo conditions. In dentistry, $\mathrm{Co}-\mathrm{Cr}$-based alloys are among the most frequently used metallic biomaterials [1-3]. In addition to the above-mentioned properties, the raw material costs of these alloys are much lower than those of the Au-based alloys previously used for dental restorations. Furthermore, these alloys are much better than $\mathrm{Ni}-\mathrm{Cr}$-based dental alloys as biomaterials because $\mathrm{Ni}$ can cause allergies and cancer in living organisms [4].

Porcelain-fused-to-metal (PFM) dental restorations are used widely in dentistry because they exhibit good mechanical rigidity and remarkable survival rates [5] and are 
aesthetically pleasing, owing to the use of ceramic veneers on the metallic framework $[6,7]$. Although casting techniques have been used to produce PFM dental restorations, recent advances in computer-aided design and computer-aided manufacturing (CAD/CAM) technology have achieved novel manufacturing routes ("CAD/CAM dentistry") [8], such as CAD/CAM-based milling [7,9] and three-dimensional (3D) printing (or additive manufacturing) [10-13]. These technologies permit the rapid and precise fabrication of custom-made dental restorations. In CAD/CAM-based milling, blank disks of metallic alloys or ceramics are used as raw materials. In contrast, 3D printing technologies (e.g., selective laser melting, electron beam melting, etc.) use metal powder to fabricate products. Unfortunately, the cost of raw powder production makes these technologies expensive at present. CAD/CAM-based milling thus remains important from a practical point of view.

Dental alloys that are used in the above-mentioned applications are now expected to exhibit high yield stresses (e.g., higher than the 500-MPa ISO22674 type 1 requirement [14]). Clasps for removable partial dentures are the primary dental application of high-strength alloys [15] because the clasps frequently loosen with time during normal daily usage [16] and because higher resistance to permanent deformation is required to suppress loss of retention and stability of the prosthesis. This application also requires high elastic modulus, fatigue strength, and toughness [17]. High fatigue strength can be achieved by increasing the (quasi-)static strength of the alloys. An increase in strength is thus necessary to improve the durability of restorations that are subjected to occlusal forces. Although casting has been employed to produce disc blanks for dental milling, it is difficult to achieve such high strengths in cast alloys. Therefore, a high-strength $\mathrm{Co}-\mathrm{Cr}$ alloy disk (DENTAURUM remanium $^{\circledR}$ star MD I) that is produced by powder metallurgy (PM) has been commercialized. In addition, thermomechanical processing (TMP) has been found to be quite effective in strengthening $\mathrm{Co}^{-} \mathrm{Cr}-$ based dental alloys $[18,19]$. 
In addition to increased strength, improved ductility (formability) is desired for these alloys because the brittle nature of as-cast alloys is detrimental to the durability of restorations. Recent research has revealed that the addition of nitrogen can improve the ductility of biomedical $\mathrm{Co}-\mathrm{Cr}$ alloys [14,20-22] and that increasing $\mathrm{Cr}$ and $\mathrm{N}$ concentrations simultaneously is particularly effective in improving ductility in as-cast alloys $[14,20]$. Furthermore, improved deformability permits more precise adjustments of restorations to individual patients, even after their clinical uses. This provides a new functionality that is beneficial for patients because the quality of fit of restorations often worsens during use.

Here, we present a design approach to obtaining high strength and good ductility (formability) in Ni-free $\mathrm{Co}-\mathrm{Cr}$-based alloys by conventional casting - a simpler, more cost-effective, industrially friendly manufacturing process than TMP or PM. For these purposes, the simultaneous addition of nitrogen and carbon, accompanied by increasing of the Cr content, is employed. The effectiveness of this concept was confirmed by using as-cast $\mathrm{Co}-33 \mathrm{Cr}-9 \mathrm{~W}-0.35 \mathrm{~N}-\mathrm{C}$ (mass $\%$ ) alloys, the chemical compositions of which were determined based on commercial $\mathrm{Co}-28 \mathrm{Cr}-9 \mathrm{~W}$ alloys. The dependence of the microstructure and mechanical properties on the carbon concentration was examined for the purpose of optimizing the chemical compositions. The corrosion resistance of the alloys developed was also evaluated via static immersion testing with systematic surface analyses.

\section{Alloy design}

The basics of the design strategy for high-strength $\mathrm{Co}-\mathrm{Cr}-\mathrm{W}$-based cast alloys for biomedical applications are briefly described, along with the results of thermodynamic calculations. The phase diagrams shown were constructed using the Thermo-Calc 4.0 software with the TCS Steels/Fe-alloys Database Ver. 6 thermodynamic database.

Figure 1a shows a vertical section of the calculated phase diagram for the $\mathrm{Co}-33 \mathrm{Cr}-$ 
$9 \mathrm{~W}-\mathrm{N}(\operatorname{mass} \%)$ system. The calculated phase diagram indicates that the face-centered cubic (fcc) $\gamma$-phase is stable at temperatures higher than $\sim 1100 \mathrm{~K}$, while the equilibrium matrix at room temperature is the hexagonal close-packed (hcp) $\varepsilon$-phase. Nitrogen was selected as an additive to improve ductility, as increasing the nitrogen concentration stabilizes the $\gamma$-phase. The addition of nitrogen was found to effectively stabilize the $\gamma$-phase by suppressing the athermal $\gamma \rightarrow \varepsilon$ martensitic transformation that occurs during cooling and is often detrimental to ductility $[21,22]$. In general, the nitrogen-stabilized $\gamma$-phase is not thermodynamically stable and can transform to the $\varepsilon$-martensite phase during subsequent plastic deformation at room temperature. The increased $\mathrm{Cr}$ content ( 33 mass $\%)$ is beneficial to increasing the nitrogen concentration of the alloys and results in higher $\gamma$-phase stability $[14,20]$, although the addition of chromium stabilizes the $\varepsilon$ phase [23] and basically does not strengthen the alloys [14]. It has been reported that the nanostructural evolution that is related to the $\mathrm{Cr}_{2} \mathrm{~N}$ phase (hexagonal, space group: $P \overline{3} 1 \mathrm{~m}$ ), which is a stable phase in this system, is a possible reason for the enhanced $\gamma$-phase stabilization $[21,22]$. Nitride precipitation also strengthens the alloys $[14,20,22,24]$. The intermetallic compound, namely, the $\sigma$-phase (close-packed tetragonal, space group: $P 4_{2} / \mathrm{mnm}$ ) exists with the $\gamma$ - or $\varepsilon$-phases over wide temperature and composition ranges. The $\sigma$-phase does not strengthen the alloys [25] and should be avoided because it has been identified as an undesirable brittle phase. It should be noted that increasing the tungsten content stabilizes the $\gamma$-phase, but excessive tungsten content results in an increase in the volume fraction of the $\sigma$-phase [26]. Adding nitrogen can also retard $\sigma$-phase precipitation $[14,20]$, but $\sigma$-phase precipitation can occur as a result of heat treating of the alloys [27]. Therefore, the addition of nitrogen is expected to improve both the strength and ductility of as-cast alloys. In addition, the intermetallic compound R-phase (rhombohedral, 
space group: $R \overline{3}$ ), which is rich in tungsten ${ }^{1}$, appears only in the low-temperature regions.

The dependence of the constituent phases on the carbon content was evaluated for the Co-33Cr-9W-0.35N-C system (Fig. 1b). Carbon was added primarily to strengthen the alloys by introducing carbide precipitates. Thermodynamic calculations indicated that the carbon solubility of the $\gamma$-matrix at elevated temperatures increases to a maximum value of $\sim 0.25$ mass $\%$ at $1550 \mathrm{~K}$ (Fig. 1b), which is much higher than in the system with the lower $\mathrm{Cr}$ content ( $\mathrm{Co}-28 \mathrm{Cr}-9 \mathrm{~W}-\mathrm{C}, \sim 0.10$ mass $\%)$ [28]. The $\mathrm{M}_{23} \mathrm{C}_{6}$-type carbide (cubic, space group: $F m \overline{3} m$ ) becomes stable at higher carbon concentrations. However, the carbon concentration should be optimized because carbide precipitation may reduce the ductility and adversely affect the corrosion resistance. The addition of carbon also stabilizes the $\gamma$-phase $[19,28]$.

\section{Materials and methods}

\subsection{Sample preparation}

We used high-frequency induction melting to prepare $\mathrm{Co}-33 \mathrm{Cr}-9 \mathrm{~W}-0.35 \mathrm{~N}-\mathrm{C}$ (mass\%) alloys in an argon atmosphere. Five 15-mm-diameter, 200 -mm-long ingots were cast in a steel mold. $\mathrm{Cr}_{2} \mathrm{~N}$ powder was used as the nitrogen source. $\mathrm{The} \mathrm{Cr}_{2} \mathrm{~N}$ powder was considered to be almost completely dissolved into the melt and a portion of the nitrogen is typically lost to the atmosphere (i.e., the yield ratio of nitrogen is less than 1). Therefore, excess amounts of $\mathrm{Cr}_{2} \mathrm{~N}$ powder were added, and the amounts of $\mathrm{Cr}$ raw material were slightly reduced from 33 mass $\%$ so that the total $\mathrm{Cr}$ concentration of each alloy after adding the $\mathrm{Cr}_{2} \mathrm{~N}$ powder was 33 mass $\%$. Therefore, we were able to evaluate the phase constituents

\footnotetext{
${ }^{1}(\mathrm{Co}, \mathrm{Cr})_{27}(\mathrm{~W}, \mathrm{Co}, \mathrm{Cr})_{18}(\mathrm{~W})_{8}$ for $\mathrm{Co}-\mathrm{Cr}-\mathrm{W}$ ternary system [39]: An example of chemical composition of the R-phase obtained by Thermo-Calc is 32.3 mass $\% \mathrm{Co}, 11.4$ mass $\% \mathrm{Cr}$, and 56.3 mass $\% \mathrm{~W}(51.1 \mathrm{at} \% \mathrm{Co}, 20.4 \mathrm{at} \% \mathrm{Cr}$, and $28.5 \mathrm{at} \% \mathrm{~W})$.
} 
of the prepared alloys based on the thermodynamic calculations. The chemical compositions of the alloys were determined by convectional chemical and gas analyses. The concentrations of the metallic elements were evaluated using an inductively coupled plasma optical emission spectrometer (ICP-OES; Thermo Fisher Scientific IRIS Advantage DUO). The carbon concentrations were determined using a combustion-infrared absorption method (Leco CS-444 LS), and the nitrogen and oxygen concentrations were determined using a He-carrier fusion-thermal conductivity method (Leco TC-436). Table 1 presents the measured chemical compositions of the alloys. The nickel contents of all of the alloys were $<0.01$ mass $\%$. These alloys are hereinafter referred to as the $0.01 \mathrm{C}, 0.06 \mathrm{C}, 0.10 \mathrm{C}, 0.25 \mathrm{C}$, and $0.31 \mathrm{C}$ alloys, in accordance with the carbon concentration of each alloy. Note that the carbon concentration of 0.01 mass $\%$ represents the impurity concentration.

\subsection{Microstructural characterization}

X-ray diffraction (XRD) measurements were obtained using a PANalytical X'Pert MPD diffractometer with $\mathrm{Cu}-\mathrm{K} \alpha$ radiation. The as-cast microstructures were investigated using a field-emission scanning electron microscope (FE-SEM) and a field-emission electron probe for microanalysis (FE-EPMA; JEOL JXA-8430F), both of which were operated at an acceleration voltage of $15 \mathrm{kV}$. The area fractions of the precipitates were evaluated using the ImageJ image analysis software (National Institutes of Health). Electron backscatter diffraction (EBSD) measurements were performed using an FE-SEM (FEI XL30S-FEG) operated at $20 \mathrm{kV}$. An orientation image microscope (OIM; TexSEM Laboratories, Inc.) system was used to accumulate and analyze the EBSD data, with a $1.5-\mu \mathrm{m}$ step in the hexagonal scan grid. The samples used for the XRD, SEM, EPMA, and EBSD analyses were mechanically ground and subsequently polished using emery papers and a $0.3-\mu \mathrm{m}$ alumina suspension and were then mirror polished using a $0.04-\mu \mathrm{m}$ colloidal silica solution. 
Transmission electron microscopy (TEM) was performed using a Topcon EM002B system operated at $200 \mathrm{kV}$. The TEM samples were prepared using a focused ion beam device (FEI QUANTA 200 3D).

\subsection{Mechanical characterization}

The Young's moduli of the as-cast alloys were measured by a free resonance method (JE-RT, Nihon Techno-Plus Co., Ltd.). Rectangular plate specimens with dimensions of $30 \times$ $10 \times 1 \mathrm{~mm}^{3}$ were cut from the as-cast specimens of each alloy and polished with 800 -grit emery paper. The measurements were performed at room temperature in air a minimum of three times for each specimen, and the average values and standard deviations were calculated.

Microindentation hardness measurements were made using an HMV Vickers microhardness tester (Shimadzu Corporation). A force of $9.8 \mathrm{~N}$ was applied for an indentation time of $10 \mathrm{~s}$. The average hardness and standard deviation were calculated.

Uniaxial tensile tests were performed on the specimens at room temperature, using tensile specimens $10.5 \mathrm{~mm}$ in gauge length, $2.0 \mathrm{~mm}$ in gauge width, and $1.0 \mathrm{~mm}$ in thickness. The tensile test specimens were cut from the cast ingots using electric discharge machining. The loading direction during the tensile testing was parallel to the longitudinal direction of the cast ingots. The specimens were strained to failure at an initial strain rate of $1.6 \times 10^{-4} \mathrm{~s}^{-1}$. We performed tensile tests at least three times on each specimen and calculated the averages and standard deviations of the $0.2 \%$ proof stress $\left(\sigma_{0.2}\right)$, the ultimate tensile strength, and the elongation to failure. We also used a FE-SEM (JEOL JSM-7100F), operated at $15 \mathrm{kV}$, to observe the fracture surfaces of the tensile-tested specimens.

\subsection{Static immersion tests}


Static immersion tests were performed in accordance with the JIS ${ }^{2}$ T 0304 standard to evaluate the effect of the carbon concentration on the corrosion resistance of the alloys. Plate specimens measuring $30 \mathrm{~mm}$ in length, $10 \mathrm{~mm}$ in width, and $1 \mathrm{~mm}$ in thickness were cut from the as-cast specimens of each alloy and polished with 800-grit emery paper. After ultrasonic cleaning in water and ethanol, the plate specimens were placed into separate polypropylene bottles that had been carefully cleaned with a 10 vol. $\% \mathrm{HNO}_{3}$ (nitric acid) solution and then rinsed with ultrapure water. A $30-\mathrm{ml}$ aliquot of a $0.6 \% \mathrm{NaCl}+1 \%$ lactic acid solution was then added to each bottle. All the bottles were placed inside an incubator that was maintained at a temperature of $310 \mathrm{~K}$ for seven days. The amounts of $\mathrm{Co}, \mathrm{Cr}, \mathrm{W}$, and $\mathrm{Ni}$ ions released from each alloy during the seven-day period were evaluated by ICP-OES (Thermo Fisher Scientific IRIS Advantage DUO), and the average amounts and standard deviations were calculated. Two groups of alloys at a time were compared using a two-tailed Student's t-test. A $p$ value of $<0.05$ was considered statistically significant.

\subsection{Surface characterization}

To determine the chemical states and compositions of the surface oxide films before and after the immersion tests, X-ray photoelectron spectroscopy (XPS) (Kratos Axis Ultra DLD) was performed using monochromated $\mathrm{Al} \mathrm{K \alpha} \mathrm{X}$-rays with an energy of $1486.7 \mathrm{eV}$. The analysis area for these measurements was $300 \times 700 \mu \mathrm{m}$. The step sizes for the measurements were $1 \mathrm{eV}$ and $0.1 \mathrm{eV}$ in the survey scans and regional scans, respectively. The chemical states of the elements were determined from the peak positions determined by deconvoluting the high-resolution scan spectra, in keeping with Ref. [29]. The samples used in the XPS analysis were prepared by the metallographic polishing procedure described above. After

\footnotetext{
2 JIS: Japanese Industrial Standard
} 
polishing, the samples were ultrasonically rinsed in acetone and ethanol and then air-dried. XPS analysis was also conducted on the samples after static immersion tests. No additional surface treatment was applied to these samples before the XPS measurements.

\section{Results}

\subsection{Microstructures}

Figure 2 shows the XRD patterns for the as-cast $\mathrm{Co}-33 \mathrm{Cr}-9 \mathrm{~W}-0.35 \mathrm{~N}-\mathrm{C}$ alloys. All of the alloys exhibited primarily $\gamma$-peaks, and no reflections assignable to the $\varepsilon$-phase were identified. Humps were observed on the left shoulder of each $\gamma$-peak for all specimens. Solidification segregation of tungsten, which has a larger atomic number than other alloying elements, occurred in the $\gamma$-matrix of the alloys, as shown later. This may result in some peak splitting or shifts to lower $2 \theta$. We can see the additional peaks, which indicate secondary phase precipitation, in the XRD patterns of the high-carbon alloys, although their intensities were quite low.

Figure 3 shows the results of the EBSD analysis of the as-cast $\mathrm{Co}-33 \mathrm{Cr}-9 \mathrm{~W}-0.35 \mathrm{~N}-\mathrm{C}$ alloys. Because the $\varepsilon$-phase was not identified in all of the alloys prepared, the (a-e) inverse pole figure (IPF) maps and ( $\mathrm{f}-\mathrm{j})$ boundary maps are presented only for the $\gamma$-phase. Cellular dendritic microstructures that are mostly separated by high-angle boundaries (HABs) can be seen in all of the alloy specimens. There were few annealing twin boundaries (ATBs).

Typical grain size distributions that were determined by EBSD analyses for each alloy are shown in Figs. $4 \mathrm{a}-\mathrm{e}$. The average grain sizes $(d)$ are summarized as a function of the carbon concentration (Fig. 4f). Under the casting conditions used, the grain size decreased significantly, from $\sim 100 \mu \mathrm{m}$ to $\sim 35 \mu \mathrm{m}$, as a result of the addition of 0.1 mass $\%$ of carbon, and then saturated, although no significant difference between the $0.01 \mathrm{C}$ and $0.05 \mathrm{C}$ alloys was seen. 
The SEM images of the as-cast $\mathrm{Co}-33 \mathrm{Cr}-9 \mathrm{~W}-0.35 \mathrm{~N}-\mathrm{C}$ alloys that were taken in the backscatter electron (BSE) imaging mode are shown in Figs. 5a-e. All of the alloys exhibited tungsten segregation, evidenced by brighter contrast in the SEM-BSE images, in interdendritic regions. In addition, precipitates are visible in these interdendritic regions, particularly in the high-carbon alloys (Figs. $5 \mathrm{c}-\mathrm{e}$ ). The relationship between the area fraction of the precipitates and the carbon concentration is summarized in Fig. 5f. Although there were few precipitates in the $0.01 \mathrm{C}$ alloy, the area fraction of the precipitates increased with increasing bulk carbon concentration and reached $\sim 6 \%$ for the $0.31 \mathrm{C}$ alloy. The increase was significant for carbon concentrations higher than 0.1 mass $\%$.

Figure 6 shows the SEM-BSE images and the corresponding EPMA elemental maps for the as-cast $\mathrm{Co}-33 \mathrm{Cr}-9 \mathrm{~W}-0.35 \mathrm{~N}-\mathrm{C}$ alloys. Solidification segregation, mentioned above, was clearly revealed: $\mathrm{Cr}, \mathrm{W}$, and $\mathrm{C}$ (only for the high-carbon alloys) were enriched in interdendritic regions, whereas Co was depleted from such regions. The alloys' nitrogen distributions were not obtained. Only the $0.25 \mathrm{C}$ and $0.31 \mathrm{C}$ alloys had carbon-rich precipitates in the interdendritic regions. The chemical compositions of the precipitates formed in the $0.01 \mathrm{C}$ and $0.31 \mathrm{C}$ alloys, which are representative of the low- and high-carbon alloys prepared in this study, respectively, were determined by EPMA analyses (Table 2). The precipitates in both alloys were enriched with $\mathrm{Cr}(\sim 50$ at $\%)$, while those in the $0.01 \mathrm{C}$ alloy had higher cobalt concentrations. Higher carbon concentrations were detected in the precipitates formed in the $0.31 \mathrm{C}$ alloys. The precipitates of the low-carbon alloys are considered to be the $\sigma$-phase, in accordance with the results of the thermodynamic calculation (Fig. 1). In contrast, the carbide phase can precipitate in the high-carbon alloys, as predicted by the thermodynamic calculation.

Figure $7 \mathrm{a}$ shows the TEM bright-field image for the interdendritic regions of the $0.31 \mathrm{C}$ alloy. The magnified dark-field image and corresponding selected area diffraction (SAD) 
pattern taken from the precipitates are shown in Fig. 7b. The SAD pattern indicates that the precipitates observed in this study can be characterized as the $\mathrm{M}_{23} \mathrm{C}_{6}$ carbide phase (the zone axis of the SAD pattern in Fig. $7 b$ is the [100] direction). Interestingly, the carbide precipitates

formed lamellar-like microstructures with the $\gamma$-phase, and the width of the carbide phase was less than $100 \mathrm{~nm}$. Few dislocations/precipitates were identified within the surrounding $\gamma$-matrix.

\subsection{Mechanical properties}

Figure 8a shows the carbon concentration dependence of the Young's moduli of the as-cast $\mathrm{Co}-33 \mathrm{Cr}-9 \mathrm{~W}-0.35 \mathrm{~N}-\mathrm{C}$ alloys. The Young's moduli of the $0.01 \mathrm{C}$ and $0.06 \mathrm{C}$ alloys were similar ( 200 GPa). The moduli increased to approximately $240 \mathrm{GPa}$ when the 0.10 mass $\%$ of carbon was added to the alloys. However, further addition of carbon resulted in no further changes in the Young's moduli of the alloys.

The results of the Vickers hardness measurements are plotted as a function of the bulk carbon concentration in Fig. 8b. There were no notable differences in hardness between the $0.01 \mathrm{C}, 0.06 \mathrm{C}$, and $0.10 \mathrm{C}$ alloys. However, the hardness values of the $0.25 \mathrm{C}$ and $0.31 \mathrm{C}$ alloys were much higher than those of the lower-carbon alloys.

The nominal stress-nominal strain curves for the as-cast $\mathrm{Co}-33 \mathrm{Cr}-9 \mathrm{~W}-0.35 \mathrm{~N}-\mathrm{C}$ alloys, which were obtained by performing tensile tests on alloy samples at room temperature, are shown in Fig. 9. All of the stress-strain curves show significant work hardening, followed by sudden fractures without macroscopic necking. The degree of work hardening was particularly significant for the $0.01 \mathrm{C}$ alloy.

Figure 10 summarizes the tensile properties as a function of the carbon concentration (see also Table 3). The minimum requirements of the ISO 22674 type 5 and ASTM F1537 standards are also shown for comparison, although the tensile tests performed in this study did 
not comply with these standards. As seen in Fig. 10a, the strength of the investigated as-cast Co-33Cr-9W-0.35N-C alloys was much higher than the type 5 criterion given in ISO 22764 for dental restorations $\left(\sigma_{0.2} \geq 500 \mathrm{MPa}\right)$. Increasing the bulk carbon concentration dramatically increased the $0.2 \%$ proof stress, from $596 \mathrm{MPa}$ for the $0.01 \mathrm{C}$ alloy to $725 \mathrm{MPa}$ for the $0.31 \mathrm{C}$ alloy. Surprisingly, the $\sigma_{0.2}$ values of the $0.25 \mathrm{C}$ and $0.31 \mathrm{C}$ alloys exceeded the strength level defined in the ASTM F1537 standard for wrought $\mathrm{Co}-\mathrm{Cr}-\mathrm{Mo}$ alloys for surgical applications $\left(\sigma_{0.2} \geq 700 \mathrm{MPa}\right)$. The ultimate tensile strength also increased with increasing carbon concentration, peaking at $\sim 1100 \mathrm{MPa}$ when the carbon concentration exceeded $\sim 0.1$ mass $\%$. Similarly, the elongation to failure was highly dependent on the carbon concentration (Fig. $10 \mathrm{~b}$ ), increasing to a maximum value of $\sim 40 \%$ for the alloys containing $\sim 0.1$ mass $\% \mathrm{C}$ and then gradually decreasing to a saturated value of approximately $14 \%$ for higher carbon concentrations. The relatively large standard deviations of the elongation values are primarily attributable to casting defects, such as shrinkage cavities and porosities, because we employed a relatively small ingot size of $\varphi 15 \mathrm{~mm}$ and because such defects are difficult to eliminate from tensile specimens entirely. The relationship between carbon concentration and defect formation should be addressed from the practical point of view.

The fracture surfaces of the tensile-tested specimens were investigated to determine the plastic deformation behavior of the alloys (Fig. 11). Intragranular quasi-cleavage fracture surfaces were predominantly observed in the $0.01 \mathrm{C}, 0.06 \mathrm{C}$, and $0.10 \mathrm{C}$ alloys. In contrast, both the $0.25 \mathrm{C}$ and $0.31 \mathrm{C}$ alloys exhibited interdendritic fractures, and the fracture surfaces of these two alloys were observed to be finer than those of the other alloys.

\subsection{Metal ion release}

Figure 12 shows the influence of the carbon concentration on the amounts of metal ions released to the solution during the static immersion tests. The concentrations of all of the 
metallic elements in the blank bottles were below the detection limit $(<0.006 \mathrm{ppm})$. The $\mathrm{Ni}$ concentrations were also below the detection limit for all samples because of their Ni-free nature. Although adding a small amount of carbon basically increases the amount of Co ion released to the solution, the amounts of cobalt released were comparable for the alloys with carbon concentrations of 0.06 mass $\%$ and higher. The other major metallic alloying elements (i.e., $\mathrm{Cr}$ and $\mathrm{W}$ ) were not detected in the solution after the immersion tests.

\subsection{Surface chemistry}

Figures 13a and $b$ show the results of the XPS survey analyses for the prepared alloys before and after the static immersion tests, respectively. The major peaks of various metallic elements, i.e., the Co $2 p, \mathrm{Cr} 2 p$, and $\mathrm{W} 4 f$ peaks, as well as the $\mathrm{O} 1 s$ peak, can be seen. $\mathrm{C}$ peaks were also detected. This is attributed to inevitable contamination because no apparent dependence on the bulk carbon concentration was confirmed. As expected, Ni $2 p$ peaks were not obtained for any of the alloys.

Narrow-scan profiles of the Co $2 p, \mathrm{Cr} 2 p, \mathrm{~W} 4 f$, and $\mathrm{O} 1 s$ peaks of the alloys before and after the immersion tests are presented in Figs. $14 \mathrm{a}-\mathrm{d}$ and $14 \mathrm{e}-\mathrm{h}$, respectively. The results for the $0.01 \mathrm{C}$ and $0.31 \mathrm{C}$ alloys are presented in Fig. 14 as representative of the results for the low- and high-carbon alloys, respectively. All of the metallic elements existed as both metals and oxides at detectable depths, although the fractions of each state before and after the static immersion tests were different. Co atoms were observed to exist as $\mathrm{Co}^{0}$ (metal) and $\mathrm{Co}^{2+}$ simultaneously (Fig. 14a) before immersion in the solution, whereas after immersion, $\mathrm{Co}^{0}$ predominantly existed, and the amounts of $\mathrm{Co}^{2+}$ on the surfaces of the immersed samples were significantly reduced (Fig. 14e). In contrast, the chemical states of the $\mathrm{Cr}$ atoms exhibited a tendency opposite that of the Co atoms: the metallic component was more 
dominant in the original state (Fig. 14b), whereas the $\mathrm{Cr}^{3+}$ components (i.e., $\mathrm{Cr}_{2} \mathrm{O}_{3}$ ) became apparent after immersion (Fig. 14f). Similarly, for the tungsten atoms, the oxide state $\left(\mathrm{W}^{6+}\right)$ was more pronounced in the immersed samples than in the samples before immersion (Figs. $14 \mathrm{c}$ and $\mathrm{g}$ ). The $\mathrm{O} 1 \mathrm{~s}$ peaks (Figs. 14d and $\mathrm{h}$ ) consisted of at least three peaks that originated from $\mathrm{O}^{2-}$, hydroxide or hydroxyl groups $\left(\mathrm{OH}^{-}\right)$, and hydrates and/or absorbed water $\left(\mathrm{H}_{2} \mathrm{O}\right)$ on the sample surfaces. These peaks, which cannot be indexed in accordance with the spectra data in Ref. [29], are indicated by "Unk" in Fig. 14d. However, these peaks tended to disappear on the immersed samples (Fig. 14h).

\section{Discussion}

\subsection{Effects of alloying nitrogen and carbon on solidification microstructures}

All of the $\mathrm{Co}-33 \mathrm{Cr}-9 \mathrm{~W}-0.35 \mathrm{~N}-\mathrm{C}$ alloys prepared in the present study had a single $\gamma$-matrix, and we could not detect the formation of the $\varepsilon$-phase, which is generally formed via martensitic transformation. This can be explained primarily by the alloys' nitrogen concentrations: the addition of nitrogen stabilizes the $\gamma$-phase of biomedical $\mathrm{Co}-\mathrm{Cr}$-based alloys, as described in Section 2. Increasing the $\mathrm{Cr}$ concentration could produce a higher nitrogen concentration; approximately 0.2 mass $\%$ is typically the upper limit of the nitrogen concentration for conventional $\mathrm{Co}-\mathrm{Cr}$ alloys with a $\mathrm{Cr}$ content of 28 mass $\%$.

On the other hand, carbide precipitation is primarily important in strengthening as-cast $\mathrm{Co}-\mathrm{Cr}$ alloys and has been used in conventional applications [30]. The fraction of precipitates increased with increasing bulk carbon concentration, although it was only $\sim 6 \%$ in the $0.31 \mathrm{C}$ alloy (Fig. 5f). The reduced area fraction of precipitates in the present alloys, compared with $\mathrm{Co}-28 \mathrm{Cr}-9 \mathrm{~W}-\mathrm{C}$ cast alloys $(\sim 10 \%$ [28]) prepared with the same casting procedure and using the steel mold, originated from the increased carbon solubility of the present alloys in the $\gamma$-matrix phase, as described in Section 2. Furthermore, adding nitrogen effectively suppresses 
$\sigma$-phase precipitation [20], particularly for low carbon concentrations; the formation of the $\sigma$-phase was actually less significant in the alloys with $0.01-0.10$ mass $\% \mathrm{C}$ (Fig. 5f). However, the $\sigma$-phase is still an equilibrium phase in the present alloy system over wide temperature and composition ranges (Fig. 1b). This implies that the casting condition, and in particular the cooling rate, is an important factor in reducing the brittle $\sigma$-phase as well. This is particularly important when the alloys examined in this study are used to make products by dental casting (e.g., partial denture frameworks), as the cooling rate in dental casting is sufficiently low to precipitate the $\sigma$-phase. Furthermore, the carbide precipitates showed a fine lamellar-like morphology (Fig. 7); this may result from eutectic reaction in solidification. The precipitation behavior of the alloys developed in this study should be examined in greater detail in a follow-up study.

More interestingly, we observed significant refinement of solidification microstructures as a result of the addition of carbon (Fig. 4). This grain refinement cannot be achieved only by nitrogen addition and is probably related to the precipitation of the carbide phase in interdendritic regions, as observed in a previous study [31]. However, the grain size remained almost constant when the carbon concentration was greater than 0.1 mass $\%$ (Fig. 4f), although the fraction of carbide precipitates increased dramatically at such carbon concentrations. Furthermore, a remarkable grain refinement was observed at carbon concentrations of 0.1 mass $\%$ or lower when the amounts of precipitates were low. These results suggest that the carbide precipitation predicted in the calculated phase diagram (Fig. 1b) does not necessarily occur when refined solidification microstructures are obtained. Solidification segregation of solute elements (i.e., $\mathrm{Cr}, \mathrm{W}$, and $\mathrm{C}$ ) in the interdendritic regions may be a possible reason for the reduction in the size of the microstructures; that is, the carbon may induce solidification segregation, and this phenomenon may reduce the grain size 
in solidification microstructures. Tungsten, with the lowest diffusion coefficient among the segregated elements (Table 4 [32]), is considered to be particularly effective for this purpose.

\subsection{Effects of carbon concentration on mechanical properties}

The present study revealed that the addition of carbon to $\mathrm{Co}-33 \mathrm{Cr}-9 \mathrm{~W}-0.34 \mathrm{~N}$ alloys increased the elastic moduli of they alloys (Fig. 8a), which is beneficial to the application of the alloys in clasps. Similar results have been reported for Co-29Cr-6Mo-0.2N-(0.05-0.24)C alloys [33]. As mentioned above, increasing the bulk carbon concentration leads to a decrease in grain size, solute segregation at grain boundaries, and carbide precipitation. These are all factors that may influence the elastic behavior of metallic materials. Although the $\mathrm{M}_{23} \mathrm{C}_{6}$-type carbide had a higher elastic modulus than the $\gamma$-matrix [34], the fraction of the carbide phase was not very high $(\sim 6 \%$ for the $0.31 \mathrm{C}$ alloy, see Fig. 5f), and the effect on the bulk elastic modulus was considered to be negligible. The underlying mechanisms related to the effects of grain size, segregation, and crystallographic orientations should be examined in future research.

It is well known that the work hardening behavior of fcc metals and alloys depends on their stacking fault energy (SFE), i.e., the stability of the $\gamma$-phase. Dynamic recovery that reduces work hardening becomes difficult as the SFE decreases. Because adding carbon stabilizes the $\gamma$-phase and may influence the SFE, work hardening may be reduced in high-carbon alloys. This is consistent with the fact that the $0.01 \mathrm{C}$ alloy exhibited significant work hardening in tensile testing (Fig. 9).

The tensile strength and ductility of the alloys developed in this study appear to be better than those of the as-cast $\mathrm{Co}-28 \mathrm{Cr}-9 \mathrm{~W}$-based alloys examined in a previous study. The results from Ref. [28] are presented in Table 3 for comparison. 
The $0.2 \%$ proof stress $\left(\sigma_{0.2}\right)$ of the investigated alloys can be expressed as a function of the bulk carbon concentration (Fig. 10a) and represented by the following relationship:

$$
\sigma_{0.2}=562+554 x_{C}
$$

where $x_{C}$ is the bulk carbon concentration of the alloys (in mass $\left.\%\right)$. The intercept $\left(x_{C}=0\right.$ mass \%) of Eq. (1), $562 \mathrm{MPa}$, is much higher than that of the as-cast $\mathrm{Co}-28 \mathrm{Cr}-9 \mathrm{~W}$ alloys without nitrogen addition ( $400 \mathrm{MPa})$ [28]. This can be interpreted primarily in terms of nitrogen addition. In contrast, the strengthening effect due to carbon doping of the present alloys (554 MPa/mass\%C) was slightly lower than for Co-28Cr-9W-based alloys in as-cast (623 MPa/mass\%C [28]) and hot-worked states (833 MPa/mass\%C [19]). This can be attributed to the reduced fractions of carbide precipitation in the present alloys because the $\mathrm{M}_{23} \mathrm{C}_{6}$-type carbide can strengthen $\mathrm{Co}-\mathrm{Cr}$-based alloys significantly. Interestingly, by examining Figs. $5 \mathrm{f}$ and $10 \mathrm{a}$ together, we can see that a linear correlation was not evident between the fraction of the precipitates and the $0.2 \%$ proof stress. Therefore, precipitation strengthening is not the sole factor responsible for the overall strengthening. Grain refinement is another relevant factor that contributes to the strength, as the grain size also varies dramatically with the bulk carbon concentration, particular for carbon concentrations of $\sim 0.1$ mass $\%$ or less (Fig. 4f). In contrast, the carbide precipitation predominantly increased the strength of the alloys in the higher carbon concentration range $(>0.1$ mass $\%)$, in which the grain size remained unchanged. Therefore, the strengthening observed here can be explained as a combination of the two above-mentioned mechanisms (Table 5). It should be noted that the linear correlation in Eq. (1) summarizes the contributions of multiple strengthening mechanisms but is not verified theoretically, although Eq. (1) is of practical use in describing and optimizing the strength of the alloys.

The tensile elongation of the alloys developed was substantial, in spite of the as-cast condition (Fig. 10b). A sufficiently high $\gamma$-phase stability, which results primarily from high 
nitrogen concentrations, is desirable for enhancing the plasticity of the alloys because the $\varepsilon$-martensite generally acts as a trigger for fractures [22]. A maximum ductility of $\sim 40 \%$ was obtained at $\sim 0.1$ mass $\% \mathrm{C}$. The $\mathrm{Co}-28 \mathrm{Cr}-9 \mathrm{~W}$-based cast alloys [28] exhibited a similar tendency, but the elongation-to-failure value obtained was much lower $(\sim 30 \%)$. The carbon-induced refinement of the solidification microstructure must contribute to the enhancement of ductility as well; the elongation to failure at $\leq 0.10$ mass $\% \mathrm{C}$, at which the marked grain refinement occurred, increased dramatically as the bulk carbon concentration increased. In contrast, interdendritic $\mathrm{M}_{23} \mathrm{C}_{6}$ carbide precipitation caused by further carbon addition resulted in reduced ductility (Fig. 10b). This can be viewed as a transition in the nature of the fracture surfaces from intragranular to intergranular with increasing bulk carbon concentration (Fig. 11). Nonetheless, the $0.31 \mathrm{C}$ alloy exhibited good elongation to failure (14\%) and very high strength.

\subsection{Effects of carbon concentration on corrosion properties}

The amounts of metal ions released in the static immersion tests were not significant; the amounts of Co released were comparable or superior to those seen with conventional Co-Cr-Mo alloys $\left(\sim 0.5 \mu \mathrm{g} \mathrm{cm}^{-2}[35]\right)$. This indicates that the investigated alloys have adequate corrosion resistance for biomedical applications, although further biocompatibility examinations should be performed. The enhanced corrosion resistance of the present alloys is discussed further in this section in terms of the surface chemistry before and after the immersion tests.

The chemical compositions of the outermost surfaces before and after the immersion tests, which were quantified from Fig. 14, are shown in Figs. 15a and c, respectively. No clear carbon concentration dependence of the surface chemistry on the carbon concentration was observed for either case. These results, which were more apparent for the immersed samples, 
are consistent with the negligible difference in corrosion resistance between the alloys, as shown in Fig. 12. The oxygen concentrations were as high as $60-70$ at $\%$ both before and after the immersion tests, indicating the formation of passive oxide films on the sample surfaces.

Figures $15 \mathrm{~b}$ and $\mathrm{d}$ show the relative distributions of metallic elements in the surface oxides before and after the immersion tests, respectively. The enrichment of $\mathrm{Cr}$ at the outermost surface oxide after immersion was clearly identified. This was accompanied by reduced amounts of Co. These results are consistent with those of previous studies on Co-Cr-Mo alloys [33,35-37]. Such Cr enrichment and passivation must result in good corrosion resistance of the alloys investigated.

Previous studies have shown that increased amounts of $\mathrm{Co}$ and $\mathrm{Cr}$ ions are released with increasing carbon concentration [19,37]. In contrast, Cr release to the solution was not detected for the alloys investigated. Bettinia et al. [38] reported that carbide boundaries act as preferential sites for metal dissolution and that an etching-like dissolution around Cr-rich $\mathrm{M}_{23} \mathrm{C}_{6}$ carbides occurs due to the formation of galvanic micro-cells between the $\mathrm{M}_{23} \mathrm{C}_{6}$ carbide and the surrounding $\gamma$-matrix. This means that the formation of a carbide phase is detrimental to corrosion resistance. Therefore, the negligible chromium dissolution of the alloys developed may be related to the relatively lower fraction of the precipitated carbide phase. Furthermore, the high chromium concentration of the alloys (33 mass\%) must contribute to their corrosion resistance. The relation between microstructures and corrosion properties is summarized in Table 5. The results obtained also indicate that the present alloying strategy is beneficial in enhancing corrosion resistance of as-cast $\mathrm{Co}-\mathrm{Cr}$ alloys. Note that the concentrations of $\mathrm{W}$ at the surface oxide were less (a few percent) and may not influence the corrosion resistance significantly.

\subsection{Significance of the present strategy}


As discussed above, the present alloying strategy can result in excellent mechanical properties in as-cast $\mathrm{Co}-\mathrm{Cr}$ alloys without loss of corrosion resistance. A higher elastic modulus, which is also beneficial to the application in clasps, can also be obtained. The improvement in the mechanical properties can be explained in terms of nitrogen addition, enhanced $\gamma$-phase stability, grain refinement, and carbide precipitation. The balancing of multiple strengthening mechanisms by simultaneous addition of nitrogen and carbon is quite effective for the present purpose.

Figure 16 summarizes the relationship between the $0.2 \%$ proof stress and the elongation to failure of the present $\mathrm{Co}-33 \mathrm{Cr}-9 \mathrm{~W}-0.35 \mathrm{~N}-\mathrm{C}$ alloys. Data obtained for the as-cast Co-28Cr-9W-C alloys [28], hot-rolled Co-28Cr-9W-C alloys [19], and hot-rolled Co-29Cr-6 Mo-0.2N-C alloys [33] with various carbon concentrations are shown for comparison $^{3}$. The minimum requirements of the ISO 22674 type 5 and ASTM F1537 standards are also shown. As Fig. 16 shows, the present cast alloys exhibited a better strength-ductility balance than the as-cast $\mathrm{Co}-28 \mathrm{Cr}-9 \mathrm{~W}-\mathrm{C}$ alloys. Although the hot-rolled alloys in the two different $\mathrm{Co}-\mathrm{Cr}$ systems had higher strengths than the present alloys, the ductility of the present cast alloys was comparable or superior to that of the hot-rolled alloys. As mentioned previously, both the strength and elongation of the $0.25 \mathrm{C}$ and $0.31 \mathrm{C}$ alloys satisfied the ASTM F1537 standard, although the present samples were prepared according to a simple casting process. These results suggest that the proposed alloying strategy shows promise for use in developing high-strength cast alloys with acceptable ductility. However, these results need to be verified by testing in accordance with the standardized test method in the future. In addition, this alloying strategy is attractive from a practical point of view because it can be applied to conventional metal mold casting.

\footnotetext{
3 The specimen size for tensile testing is almost same in Refs. [19,28,33].
} 
On the other hand, the Vickers hardness values of the alloys with carbon concentrations of 0.1 mass $\%$ or less were not very high (320-340 Hv, Fig. 8 b), because of the very low fraction of precipitates. The high-carbon alloys had Vickers hardness values as high as the commercial $\mathrm{Co}-\mathrm{Cr}-\mathrm{Mo}$ dental cast alloy $(370 \mathrm{Hv})$ [30] but slightly higher values than the PM-processed Co-Cr-W-based disk material (330 Hv). The higher hardness is mainly due to the hard carbide precipitates. The hardness results indicate that the alloys developed can be used as blank disks for milling dental restorations, in which the machinability of the alloys is also important. However, the high ductility of the low-carbon alloys might be detrimental for milling characteristics since it is associated with a tendency for metal to adhere to the tooling. In contrast, the present high-carbon-content alloys have adequate ductility and good corrosion resistance. Therefore, in the production of high-strength alloys (e.g., the $0.31 \mathrm{C}$ alloy), increasing the carbon concentration is still acceptable as a microstructural design strategy. To ensure that these alloys are applicable to PFM restorations, the effect of subsequent heat treatment through porcelain firing should be examined. In addition, further research on the fatigue properties and toughness of the alloys is important to ensure their suitability for use in practical applications such as in clasps.

Although the present cast alloys were developed for dental applications, they can also be used in load-bearing orthopedic applications (e.g., in $\mathrm{Co}-\mathrm{Cr}-\mathrm{Mo}$ alloys for artificial knee joints). Their fine microstructures and excellent mechanical and corrosion properties, which are comparable or superior to those of wrought $\mathrm{Co}-\mathrm{Cr}$ alloys, indicate their promise for use as novel cast implants.

\section{Conclusions}

In this paper, we have proposed a novel alloy design strategy for producing as-cast $\mathrm{Co}-\mathrm{Cr}-\mathrm{W}$-based alloys with high strength and adequate ductility. The concept was verified by 
preparing $\mathrm{Co}-33 \mathrm{Cr}-9 \mathrm{~W}-0.35 \mathrm{~N}-(0.01-0.31) \mathrm{C}(\mathrm{mass} \%)$ alloys with conventional metal mold casting and examining their microstructures, as well as their tensile properties and corrosion characteristics. The following conclusions can be drawn:

- The alloys exhibited a single $\gamma$-phase matrix, primarily because of their high nitrogen concentrations.

- Solidification segregation accompanied by precipitation was observed in interdendritic regions, resulting in finer grain structures. The proposed alloy design strategy permits a negligible amount of brittle $\sigma$-phase precipitation. Further addition of carbon resulted in an increased fraction of $\mathrm{M}_{23} \mathrm{C}_{6}$ carbide precipitates.

- The strengths of the alloys were high because of their high concentrations of nitrogen. Adding carbon to the alloys strengthened them dramatically, and the $0.2 \%$ proof stress of the alloys gradually increased with increasing carbon concentration. The elongation to failure increased when the carbon concentration was $<0.1$ mass $\%$, reaching a maximum when the carbon concentration was approximately 0.1 mass $\%$ and then decreasing with further increases in the carbon content. However, the elongation remained at least $10 \%$ when the carbon concentration was 0.31 mass $\%$. The variation in the tensile properties due to the addition of carbon to the alloys originated from the refinement of the solidification microstructures and $\mathrm{M}_{23} \mathrm{C}_{6}$ carbide precipitation.

- The results of static immersion tests in an aqueous solution of $0.6 \%$ sodium chloride $(\mathrm{NaCl})$ and 1\% lactic acid revealed that the corrosion resistance of the alloys developed is comparable or superior to that of conventional biomedical $\mathrm{Co}-\mathrm{Cr}$ alloys.

- Based on these considerations, we identified a carbon concentration of approximately 0.1 mass $\%$ as the optimum for balancing the strength and ductility of the as-cast alloys. Increasing the carbon concentration significantly increases the strength, in comparison to 
that of wrought $\mathrm{Co}-\mathrm{Cr}-\mathrm{Mo}$ alloys, while maintaining acceptable ductility and good corrosion resistance.

- To ensure that these alloys are applicable to PFM restorations, the effect of subsequent heat treatment through porcelain firing should be examined. In addition, further research is needed on the alloys' fatigue properties and toughness, both of which are important for alloys that meet the requirements for use in clasps.

\section{Acknowledgments}

We thank Daisuke Itoi, Ryo Tanno, Yuki Sato, Koji Kuramoto, Shun Ito, Yumiko Kodama, Kumiko Suzuki, and Kazuyo Ohmura for their technical assistance. This research was supported by the Grant-in-Aid for Young Scientists (B) (No. 26870050); the cooperative program (No. 14G0429) of the Cooperative Research and Development Center for Advanced Materials, Institute for Materials Research, Tohoku University; the "Nanotechnology Platform" of the Ministry of Education, Culture, Sports, Science and Technology (MEXT), Japan, at the Center for Integrated Nanotechnology Support, Tohoku University; the Inter-University Cooperative Research Program; the Innovative Research for Biosis-Abiosis Intelligent Interface, from the MEXT; and the Adaptable and Seamless Technology Transfer Program through Target-driven R\&D (A-STEP), Japan Science and Technology Agency (JST), Japan. The study design, data collection, data analysis, data interpretation, report writing, and decision to submit this article for publication were all conducted without the involvement of the funding sources.

\section{References}

[1] J.C. Wataha, Alloys for prosthodontic restorations, J. Prosthet. Dent. 87 (2002) 351-363. 
[2] J. Powers, J. Wataha, Dental materials: properties and manipulation, 10th ed., Mosby, St. Louis, 2013.

[3] R.G. Craig, J. Powers, R. Sakaguchi, Craig's restorative dental materials, 13th ed., Mosby, Philadelphia, 2012.

[4] E. Denkhaus, K. Salnikow, Nickel essentiality, toxicity, and carcinogenicity, Crit. Rev. Oncol. Hematol. 42 (2002) 35-56.

[5] M. O zcan, Fracture reasons in ceramic-fused-to-metal restorations, J. Oral Rehabil. 30 (2003) 265-269.

[6] E.D. Rekow, Dental CAD/CAM systems: A 20-year success story, J. Am. Dent. Assoc. 137 (2008) 5-6.

[7] F. Beuer, J. Schweiger, M. Eichberger, H.F. Kappert, W. Gernet, D. Edelhoff, High-strength $\mathrm{CAD} / \mathrm{CAM}$-fabricated veneering material sintered to zirconia copings-a new fabrication mode for all-ceramic restorations, Dent. Mater. 25 (2009) 121-128.

[8] Y.S. Al Jabbari, T. Koutsoukis, X. Barmpagadaki, S. Zinelis, Metallurgical and interfacial characterization of PFM Co-Cr dental alloys fabricated via casting, milling or selective laser melting, Dent. Mater. 30 (2014) e79-e88.

[9] J. Willer, A. Rossbach, H.-P. Wever, Computer-assisted milling of dental restorations using a new CAD/CAM data acquisition system, J. Prosthet. Dent. 80 (1998) 346-353.

[10] Y.S. Hedberg, B. Qian, Z. Shen, S. Virtanen, I. Odnevall Wallinder, In vitro biocompatibility of CoCrMo dental alloys fabricated by selective laser melting, Dent. Mater. 30 (2014) 525-534.

[11] M. Koike, K. Martinez, L. Guo, G. Chahine, R. Kovacevic, T. Okabe, Evaluation of titanium alloy fabricated using electron beam melting system for dental applications, J. Mater. Process. Technol. 211 (2011) 1400-1408. 
[12] A. Takaichi, Suyalatu, T. Nakamoto, N. Joko, N. Nomura, Y. Tsutsumi, et al., Microstructures and mechanical properties of Co-29Cr-6Mo alloy fabricated by selective laser melting process for dental applications, J. Mech. Behav. Biomed. Mater. $21(2013)$ 67-76.

[13] N. Xiang, X.Z. Xin, J. Chen, B. Wei, Metal-ceramic bond strength of Co-Cr alloy fabricated by selective laser melting, J. Dent. 40 (2012) 453-457.

[14] K. Yoda, Suyalatu, A. Takaichi, N. Nomura, Y. Tsutsumi, H. Doi, et al., Effects of chromium and nitrogen content on the microstructures and mechanical properties of as-cast $\mathrm{Co}-\mathrm{Cr}-\mathrm{Mo}$ alloys for dental applications, Acta Biomater. 8 (2012) 2856-2862.

[15] R. van Noort, Casting alloys for metallic restorations, in: Introd. to Dent. Mater., 4th ed., Mosby, Edinburgh ; New York, 2013: pp. 181-190.

[16] D. Kim, C. Park, Y. Yi, L. Cho, Comparison of cast Ti-Ni alloy clasp retention with conventional removable partial denture clasps, J. Prosthet. Dent. 91 (2004) 374-382.

[17] K.J. Anusavice, R.W. Phillips, C. Shen, H.R. Rawls, Phillips' Science of Dental Materials, 12th ed., Saunders, St. Louis, 2013.

[18] K. Yamanaka, M. Mori, K. Kuramoto, A. Chiba, Development of new Co-Cr-W-based biomedical alloys: Effects of microalloying and thermomechanical processing on microstructures and mechanical properties, Mater. Des. 55 (2014) 987-998.

[19] K. Yamanaka, M. Mori, A. Chiba, Influence of carbon addition on mechanical properties and microstructures of $\mathrm{Ni}$-free $\mathrm{Co}-\mathrm{Cr}-\mathrm{W}$ alloys subjected to thermomechanical processing, J. Mech. Behav. Biomed. Mater. 37 (2014) 274-285.

[20] S.-H. Lee, N. Nomura, A. Chiba, Significant Improvement in Mechanical Properties of Biomedical Co-Cr-Mo Alloys with Combination of $\mathrm{N}$ Addition and Cr-Enrichment, Mater. Trans. 49 (2008) 260-264. 
[21] K. Yamanaka, M. Mori, A. Chiba, Nanoarchitectured $\mathrm{Co}-\mathrm{Cr}-\mathrm{Mo}$ orthopedic implant alloys: nitrogen-enhanced nanostructural evolution and its effect on phase stability, Acta Biomater. 9 (2013) 6259-6267.

[22] K. Yamanaka, M. Mori, A. Chiba, Effects of nitrogen addition on microstructure and mechanical behavior of biomedical $\mathrm{Co}-\mathrm{Cr}-\mathrm{Mo}$ alloys, J. Mech. Behav. Biomed. Mater. 29 (2014) 417-426.

[23] C.T. Sims, N.S. Stoloff, W.C. Hagel, Superalloys II: High-Temperature Materials for Aerospace and Industrial Power, 2nd ed., Wiley-Interscience, New York, 1987.

[24] K. Yamanaka, M. Mori, A. Chiba, Enhanced Mechanical Properties of As-Forged CoCr-Mo-N Alloys with Ultrafine-Grained Structures, Metall. Mater. Trans. A. 43 (2012) $5243-5257$.

[25] S. Kurosu, N. Nomura, A. Chiba, Microstructure and Mechanical Properties of Co-29Cr-6Mo Alloy Aged at 1023 K, Mater. Trans. 48 (2007) 1517-1522.

[26] A. Karaali, K. Mirouh, S. Hamamda, P. Guiraldenq, Microstructural study of tungsten influence on Co-Cr alloys, Mater. Sci. Eng. A. 390 (2005) 255-259.

[27] M. Mori, K. Yamanaka, A. Chiba, Phase decomposition in biomedical Co-29Cr-6Mo0.2N alloy during isothermal heat treatment at $1073 \mathrm{~K}$, J. Alloys Compd. 520 (2014) $411-416$.

[28] K. Yamanaka, M. Mori, A. Chiba, Effects of carbon concentration on microstructure and mechanical properties of as-cast nickel-free $\mathrm{Co}-28 \mathrm{Cr}-9 \mathrm{~W}$-based dental alloys, Mater. Sci. Eng. C. 40 (2014) 127-134.

[29] J.F. Moulder, W.F. Stickle, P.E. Sobol, K.D. Bomben, Handbook of X-ray Photoelectron Spectroscopy, 2nd ed., Physical Electronics, Eden Prairie, 1995.

[30] K. Yamanaka, M. Mori, A. Chiba, Assessment of precipitation behavior in dental castings of a Co-Cr-Mo alloy, J. Mech. Behav. Biomed. Mater. 50 (2015) 268-276. 
[31] K. Yamanaka, M. Mori, A. Chiba, Refinement of solidification microstructures by carbon addition in biomedical Co-28Cr-9W-1Si alloys, Mater. Lett. 116 (2014) 82-85.

[32] Japan Institute of Metals, ed., Kinzoku Databook, 4th ed., Maruzen, Sendai, 2004.

[33] M. Mori, K. Yamanaka, K. Kuramoto, K. Ohmura, T. Ashino, A. Chiba, Effect of carbon on the microstructure, mechanical properties and metal ion release of $\mathrm{Ni}$-free $\mathrm{Co}-\mathrm{Cr}-\mathrm{Mo}$ alloys containing nitrogen, Mater. Sci. Eng. C. 55 (2015) 145-154.

[34] Y. Liao, R. Pourzal, P. Stemmer, M.A. Wimmer, J.J. Jacobs, A. Fischer, et al., New insights into hard phases of CoCrMo metal-on-metal hip replacements, J. Mech. Behav. Biomed. Mater. 12 (2012) 39-49.

[35] Y. Okazaki, E. Gotoh, Comparison of metal release from various metallic biomaterials in vitro, Biomaterials. 26 (2005) 11-21.

[36] T. Hanawa, Metal ion release from metal implants, Mater. Sci. Eng. C. 24 (2004) 745752.

[37] Y. Hedberg, I. Odnevall Wallinder, Metal release and speciation of released chromium from a biomedical CoCrMo alloy into simulated physiologically relevant solutions, J. Biomed. Mater. Res. - Part B Appl. Biomater. 102B (2013) 693-699.

[38] E. Bettini, T. Eriksson, M. Boström, C. Leygraf, J. Pan, Influence of metal carbides on dissolution behavior of biomedical CoCrMo alloy: SEM, TEM and AFM studies, Electrochim. Acta. 56 (2011) 9413-9419.

[39] B. Kaplan, A. Blomqvist, M. Selleby, S. Norgren, Thermodynamic analysis of the WCo-Cr system supported by ab initio calculations and verified with quaternary data, Calphad. 50 (2015) 59-67. 


\section{Captions}

Figure 1. Vertical sections of the calculated phase diagrams of (a) $\mathrm{Co}-33 \mathrm{Cr}-9 \mathrm{~W}-\mathrm{N}$ (mass $\%$ ) and (b) $\mathrm{Co}-33 \mathrm{Cr}-9 \mathrm{~W}-0.35 \mathrm{~N}-\mathrm{C}$ systems obtained using the Thermo-Calc software.

Figure 2. XRD patterns for as-cast Co-33Cr-9W-0.35N-C alloys prepared with various carbon contents.

Figure 3. EBSD maps of as-cast $\mathrm{Co}-33 \mathrm{Cr}-9 \mathrm{~W}-0.35 \mathrm{~N}-\mathrm{C}$ alloys prepared with various carbon contents: (a-e) IPF maps and (f-j) boundary maps of $(a, f) 0.01 C,(b, g) 0.06 C,(c, j) 0.10 C$, (d, i) $0.25 \mathrm{C}$, and $(e, j) 0.31 \mathrm{C}$ alloys, respectively. The black, green, and red lines in the boundary maps indicate high-angle boundaries (HABs) with misorientations larger than $15^{\circ}$, low-angle boundaries (LABs) with misorientations of $2^{\circ}-15^{\circ}$, and annealing twin boundaries (ATBs), respectively.

Figure 4. Typical grain size distributions of as-cast $\mathrm{Co}-33 \mathrm{Cr}-9 \mathrm{~W}-0.35 \mathrm{~N}-\mathrm{C}$ alloys: (a) $0.01 \mathrm{C}$, (b) $0.06 \mathrm{C}$, (c) $0.10 \mathrm{C}$, (d) $0.25 \mathrm{C}$, and (e) $0.31 \mathrm{C}$. The average grain sizes of the samples are shown in (f).

Figure 5. SEM-BSE images of as-cast $\mathrm{Co}-33 \mathrm{Cr}-9 \mathrm{~W}-0.35 \mathrm{~N}-\mathrm{C}$ alloys: (a) $0.01 \mathrm{C}$, (b) $0.06 \mathrm{C}$, (c) $0.10 \mathrm{C}$, (d) $0.25 \mathrm{C}$, and (e) $0.31 \mathrm{C}$. The area fraction of precipitates as a function of the bulk carbon concentration is shown in (f).

Figure 6. SEM-BSE images and corresponding EPMA elemental maps for as-cast $\mathrm{Co}-33 \mathrm{Cr}-$ 9W-0.35N-C alloys: (a) $0.01 \mathrm{C}$, (b) $0.06 \mathrm{C}$, (c) $0.10 \mathrm{C}$, (d) $0.25 \mathrm{C}$, and (e) $0.31 \mathrm{C}$.

Figure 7. (a) TEM bright-field image and (b) magnified dark-field image of $M_{23} C_{6}$ phase precipitated in the as-cast $0.31 \mathrm{C}$ alloy. The SAD pattern taken from the carbide phase is also shown in (b).

Figure 8. Dependence of (a) Young's modulus and (b) Vickers hardness on carbon concentration of as-cast $\mathrm{Co}-33 \mathrm{Cr}-9 \mathrm{~W}-0.35 \mathrm{~N}-\mathrm{C}$ alloys. 
Figure 9. Tensile stress-strain curves for as-cast $\mathrm{Co}-33 \mathrm{Cr}-9 \mathrm{~W}-0.35 \mathrm{~N}-\mathrm{C}$ alloys prepared with various carbon concentrations.

Figure 10. Tensile properties of as-cast $\mathrm{Co}-33 \mathrm{Cr}-9 \mathrm{~W}-0.35 \mathrm{~N}-\mathrm{C}$ alloys plotted as functions of carbon concentrations: (a) strength and (b) elongation to failure.

Figure 11. Fracture surfaces of as-cast $\mathrm{Co}-33 \mathrm{Cr}-9 \mathrm{~W}-0.35 \mathrm{~N}-\mathrm{C}$ alloys: (a, f) $0.01 \mathrm{C}$, (b, g) 0.06C, $(c, j) 0.10 C,(d, i) 0.25 C$, and $(e, j) 0.31 C$. Magnified images of $(a-e)$ are shown in $(\mathrm{f}-\mathrm{j})$, respectively.

Figure 12. Concentration of metal ions released from as-cast $\mathrm{Co}-33 \mathrm{Cr}-9 \mathrm{~W}-0.35 \mathrm{~N}-\mathrm{C}$ alloys during static immersion testing. Asterisks indicate significant differences between indicated groups; $* p<0.05, * * p \geq 0.05$.

Figure 13. XPS survey scans of as-cast $\mathrm{Co}-33 \mathrm{Cr}-9 \mathrm{~W}-0.35 \mathrm{~N}-\mathrm{C}$ alloys prepared in this study: (a) before and (b) after static immersion testing.

Figure 14. XPS elemental binding analysis envelopes of the (a, e) $\mathrm{Co} 2 p,(\mathrm{~b}, \mathrm{f}) \mathrm{Cr} 2 p,(\mathrm{c}, \mathrm{g})$ $\mathrm{W} 4 f$, and $(\mathrm{d}, \mathrm{h}) \mathrm{O} 1 s$ peaks of as-cast $\mathrm{Co}-33 \mathrm{Cr}-9 \mathrm{~W}-0.35 \mathrm{~N}-\mathrm{C}$ alloys with different carbon concentrations and their deconvolution into their component peaks.

Figure 15. $(a, c)$ Compositions of surface oxide films and $(b, d)$ relative contents of metals in surface oxides of as-cast $\mathrm{Co}-33 \mathrm{Cr}-9 \mathrm{~W}-0.35 \mathrm{~N}-\mathrm{C}$ alloys: $(\mathrm{a}, \mathrm{b})$ before and $(\mathrm{c}, \mathrm{d})$ after static immersion tests.

Figure 16. Relationship between the elongation to failure and $0.2 \%$ proof stress of the Co$33 \mathrm{Cr}-9 \mathrm{~W}-0.35 \mathrm{~N}-\mathrm{C}$ alloys developed in this study. The data obtained for the as-cast $\mathrm{Co}-$ 28Cr-9W-C alloys [28], hot-rolled Co-28Cr-9W-C alloys [19], and hot-rolled Co-29Cr-6 Mo-0.2N-C alloys [33] are also shown for comparison.

Table 1. Chemical compositions (mass $\%$ ) of the $\mathrm{Co}-33 \mathrm{Cr}-9 \mathrm{~W}-0.35 \mathrm{~N}-\mathrm{C}$ alloys prepared in this study. 
Table 2. Chemical compositions (at $\%$ ) of precipitates formed in the as-cast $\mathrm{Co}-33 \mathrm{Cr}-9 \mathrm{~W}-$ $0.35 \mathrm{~N}-\mathrm{C}$ alloys.

Table 3. Tensile properties of the as-cast $\mathrm{Co}-33 \mathrm{Cr}-9 \mathrm{~W}-0.35 \mathrm{~N}-\mathrm{C}$ alloys. Test results for previous as-cast $\mathrm{Co}-28 \mathrm{Cr}-9 \mathrm{~W}$-based alloys [28] are presented for comparison.

Table 4. Diffusion parameters $\left(D_{0}, Q\right)$ for $\mathrm{Co}, \mathrm{Cr}, \mathrm{W}$, and $\mathrm{Si}$ in $\gamma \mathrm{Co}$ [32].

Table 5. Correlation between microstructures and mechanical and corrosion properties of the as-cast $\mathrm{Co}-33 \mathrm{Cr}-9 \mathrm{~W}-0.35 \mathrm{~N}-\mathrm{C}$ alloys. 


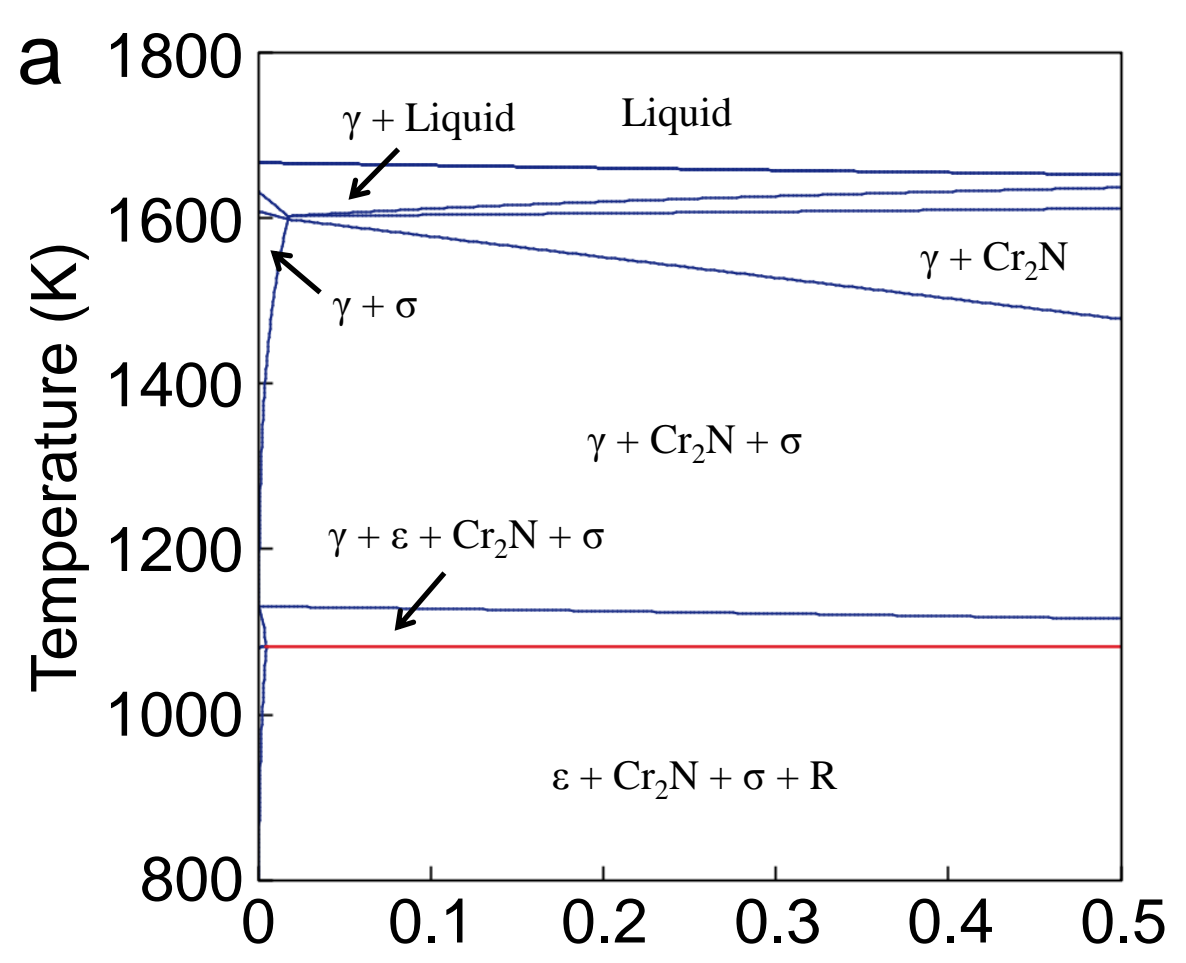

Nitrogen concentration (mass\%)

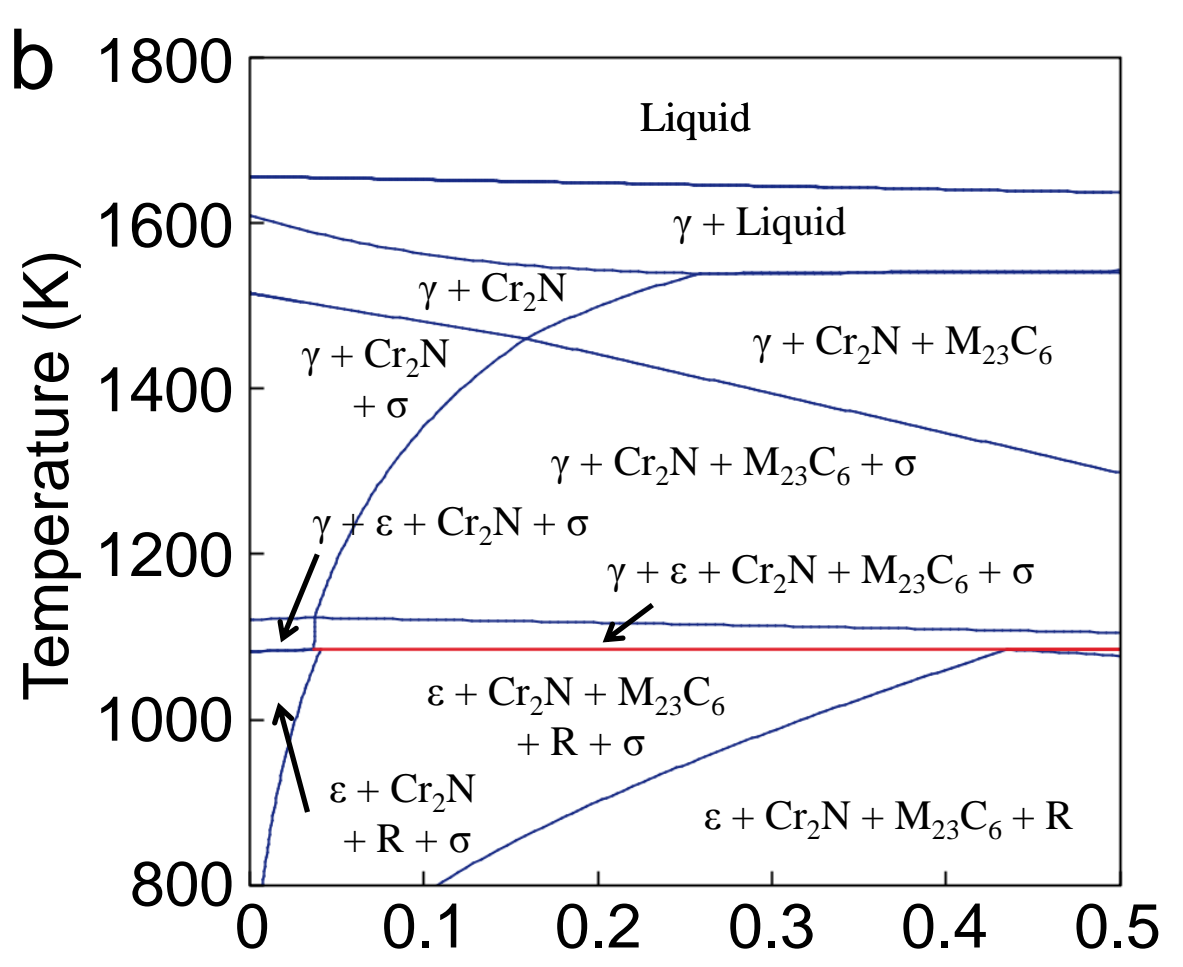

Carbon concentration (mass\%)

Figure 1 


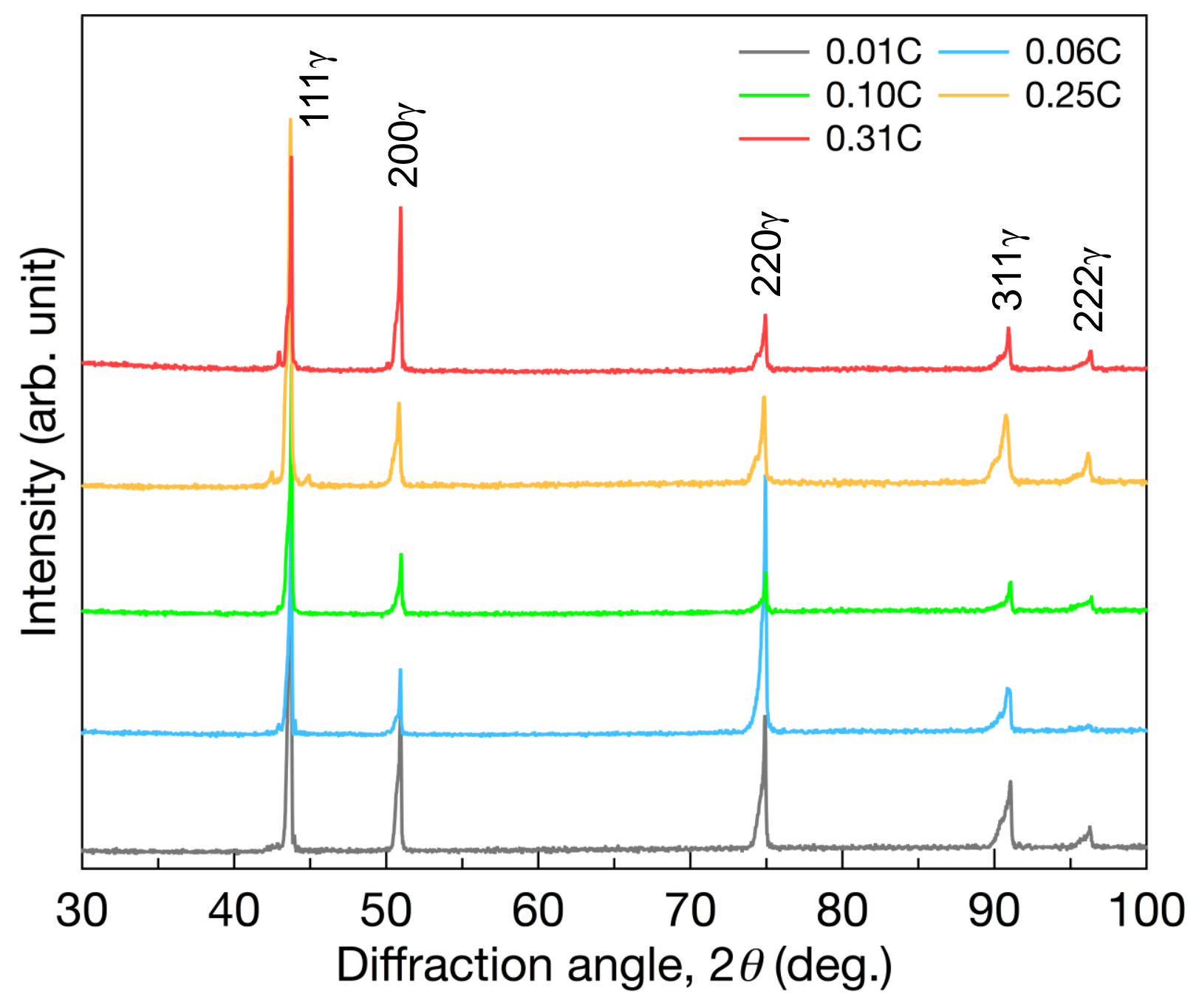

Figure 2 

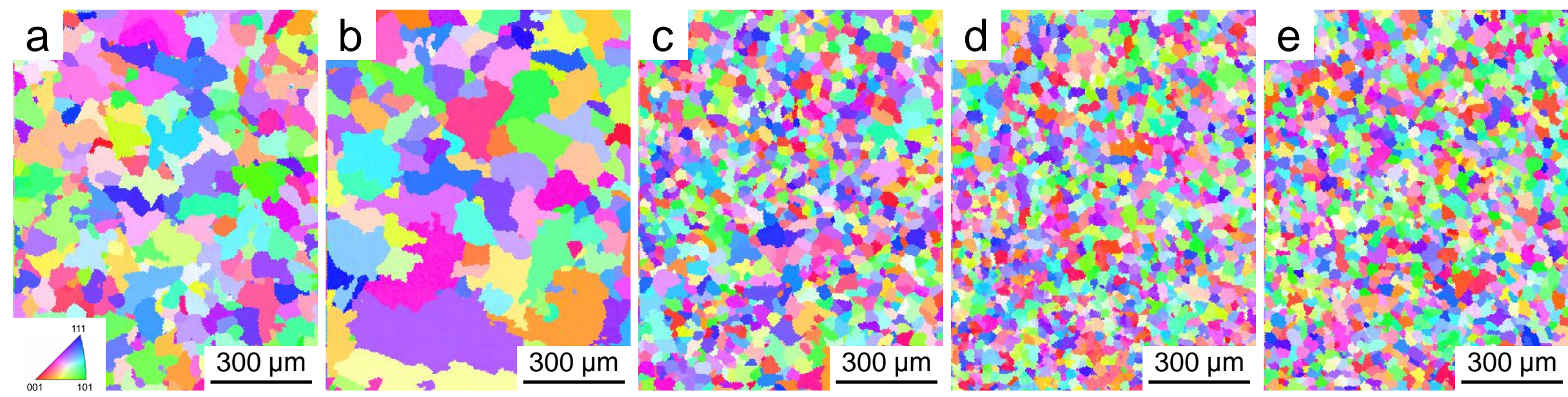

$f$ and

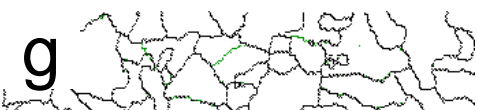

$h$ r $3 x^{2},-3 x$

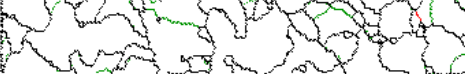
and a

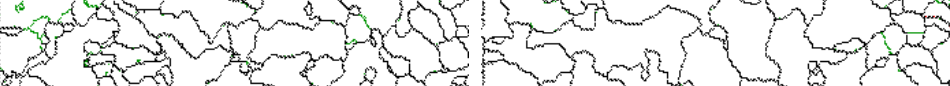

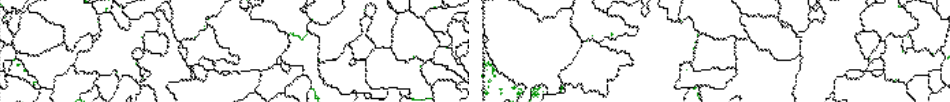
S. $-2^{\circ}<\theta<15$ $300 \mu \mathrm{m}$

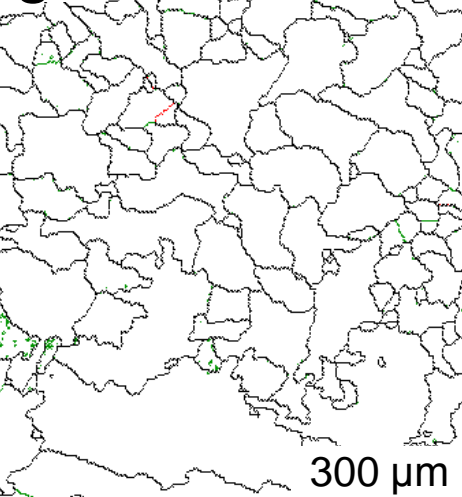

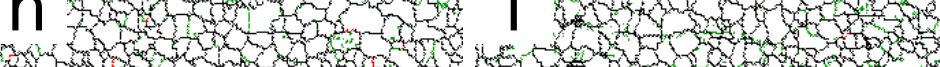

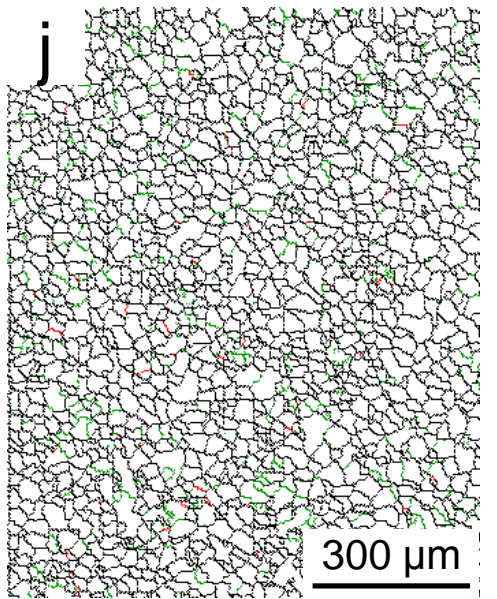

Figure 3

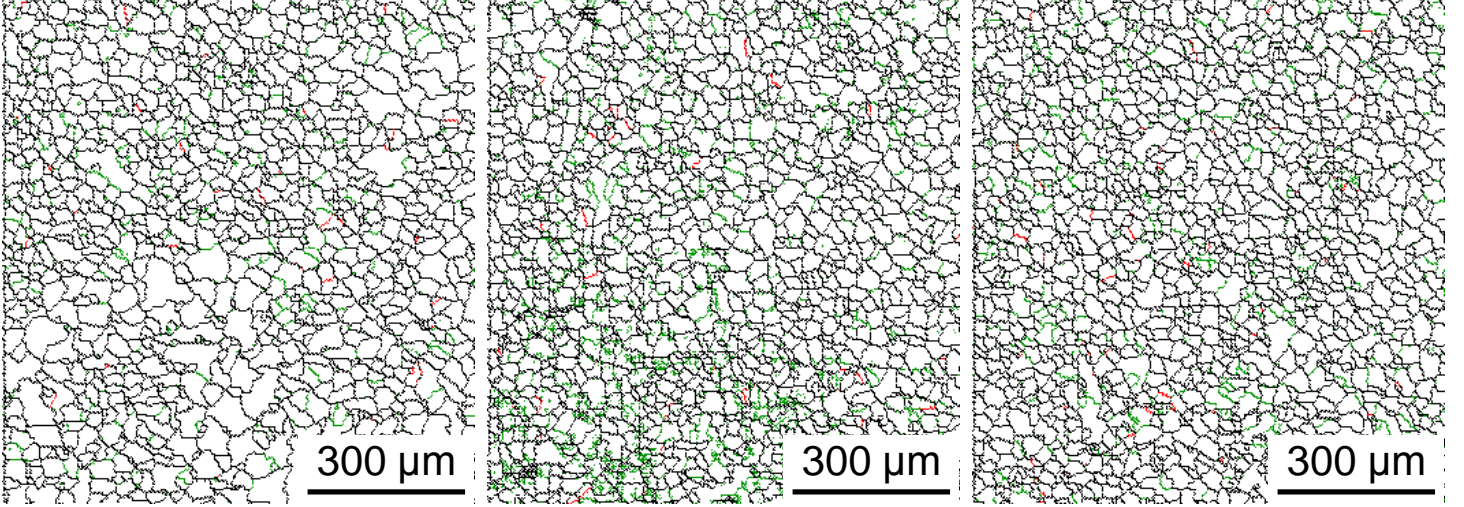



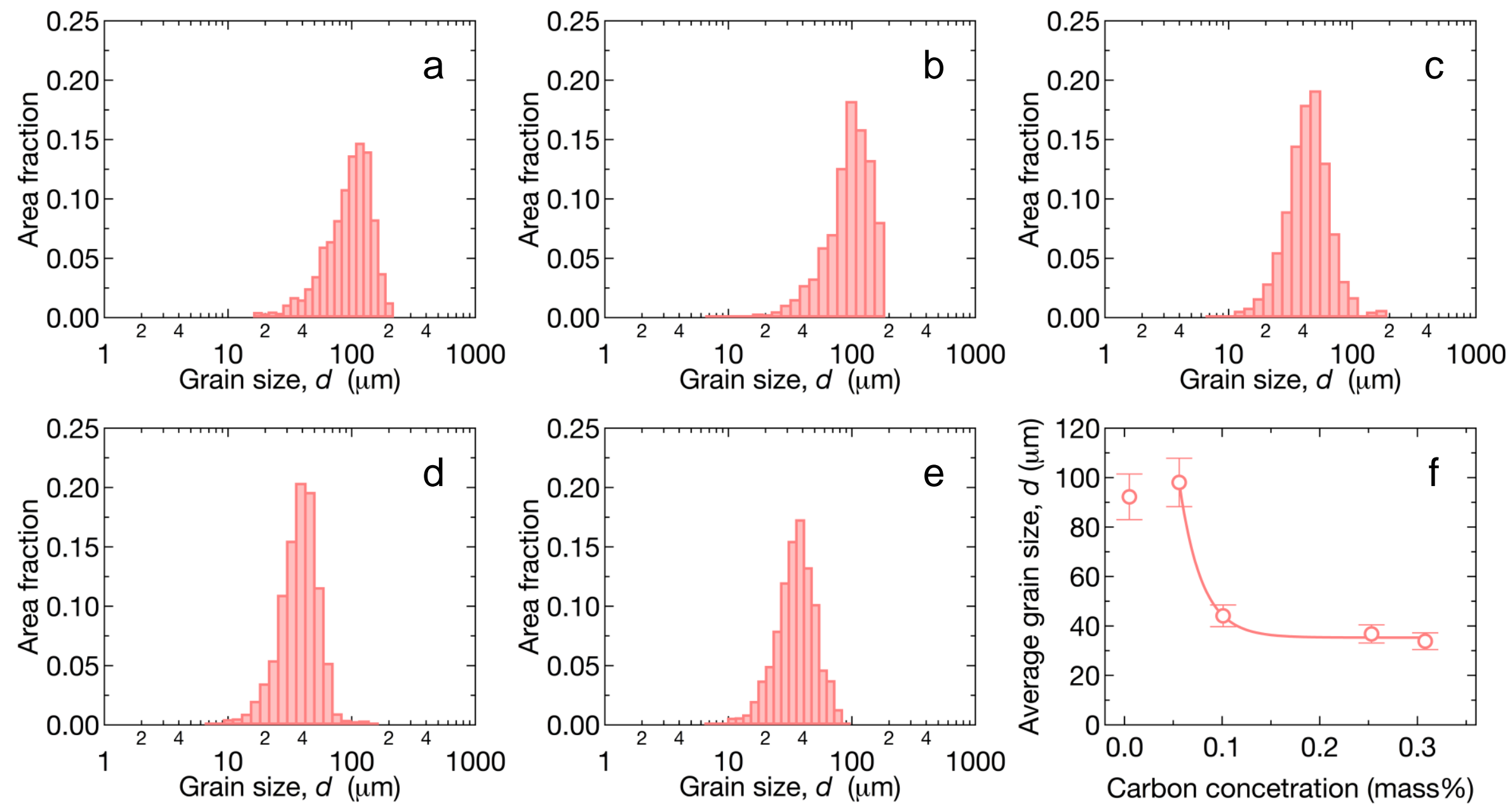

Figure 4 


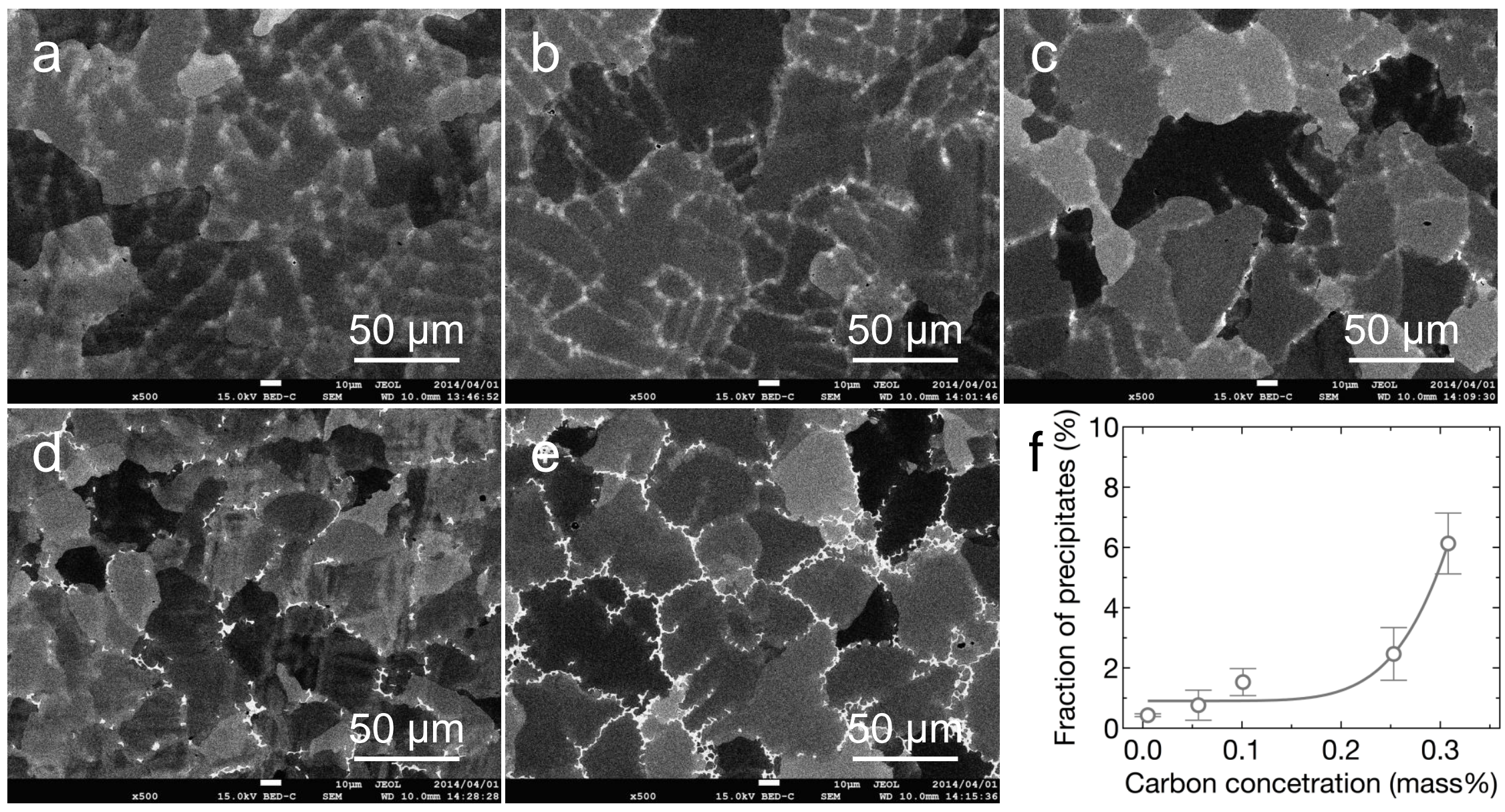

Figure 5 


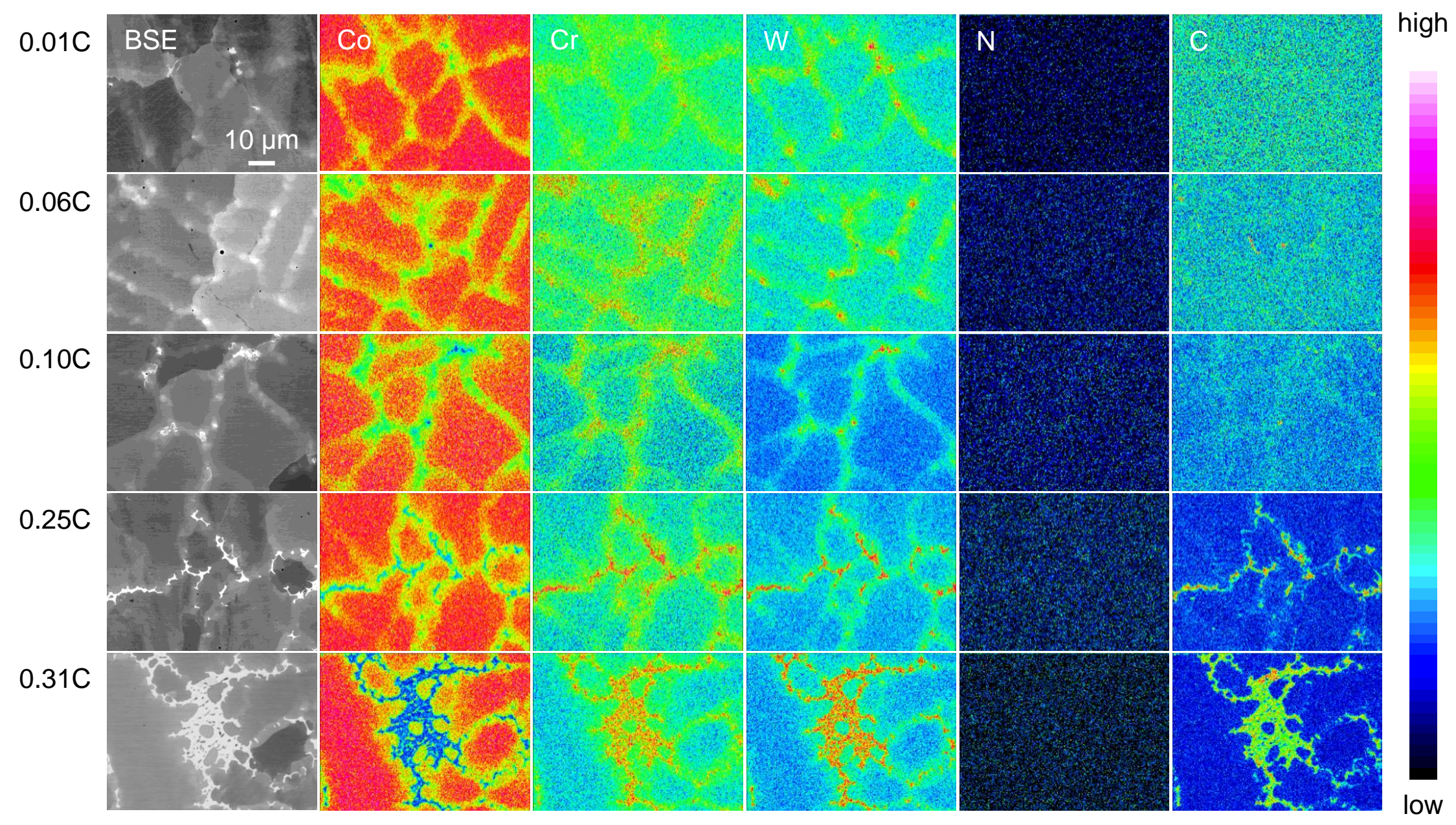

Figure 6 

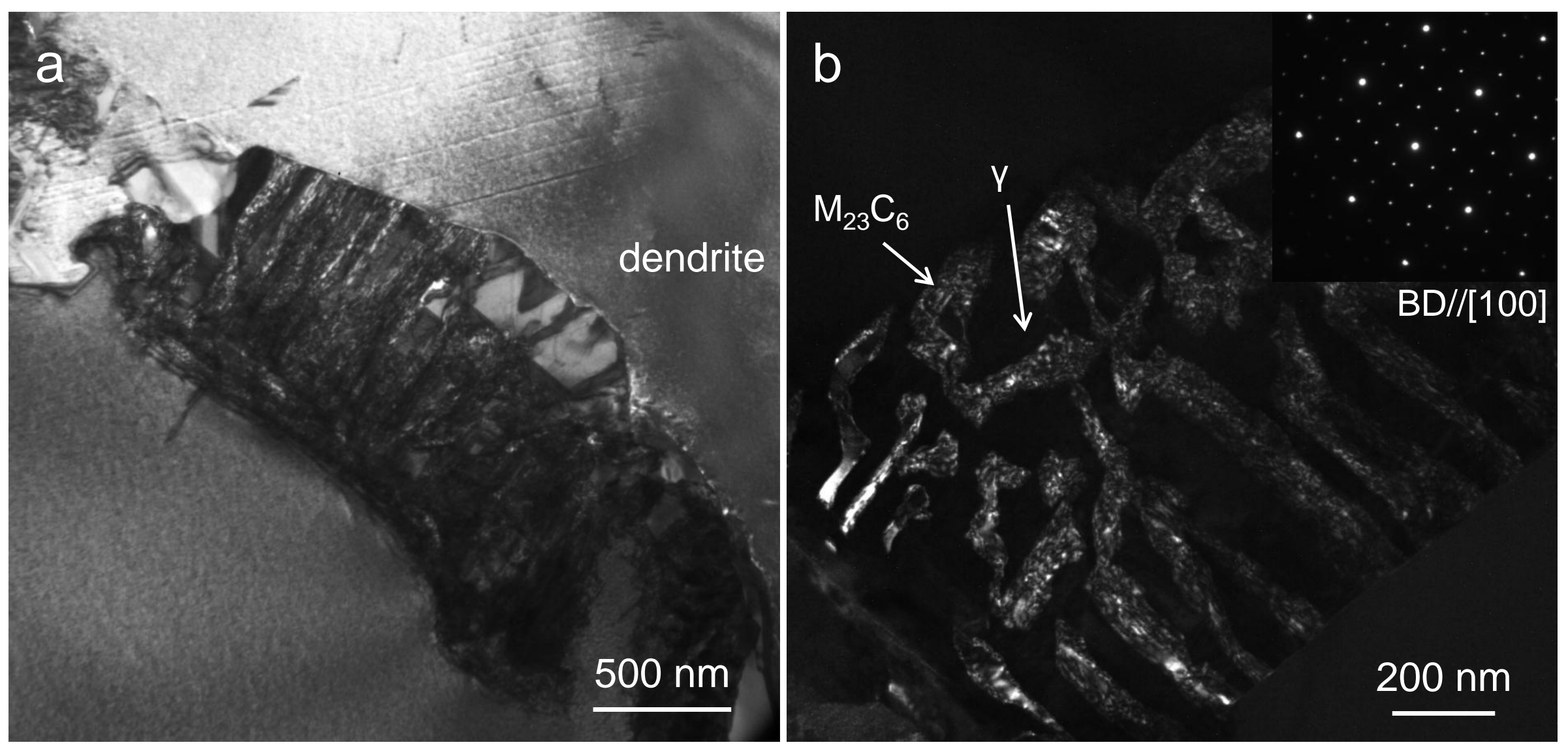

Figure 7 
a

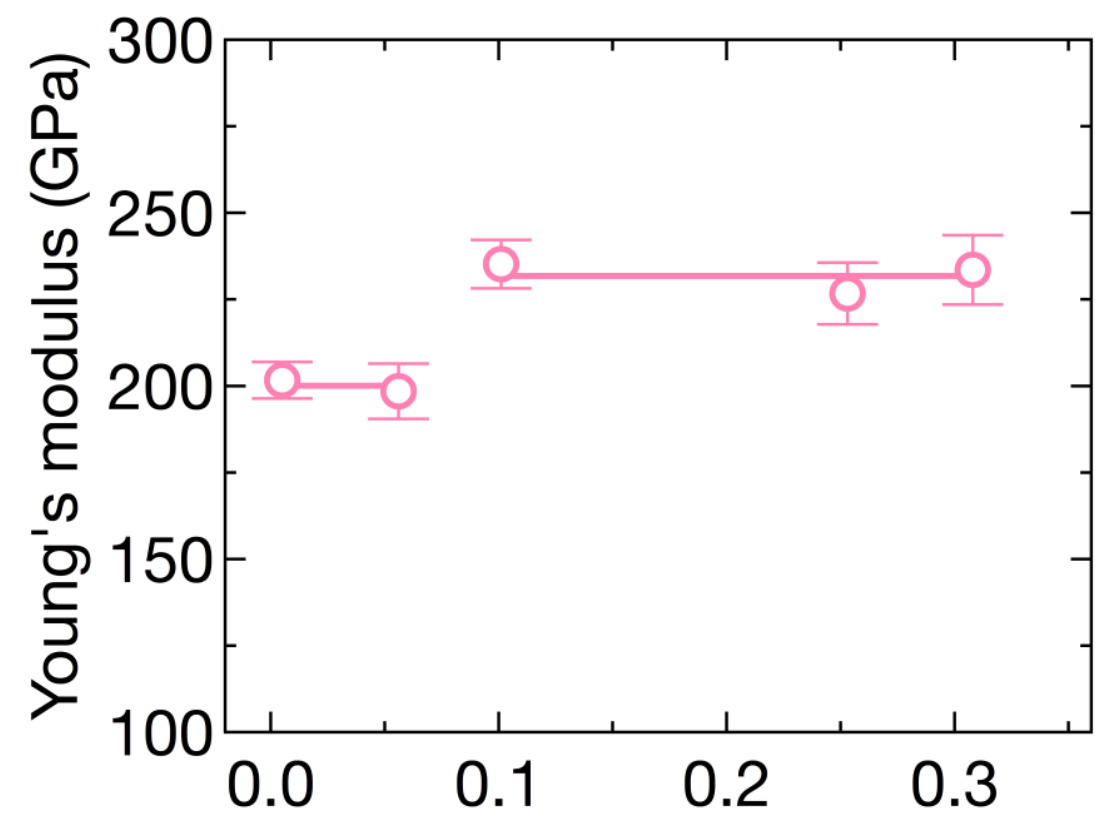

Carbon concetration (mass $\%$ ) b

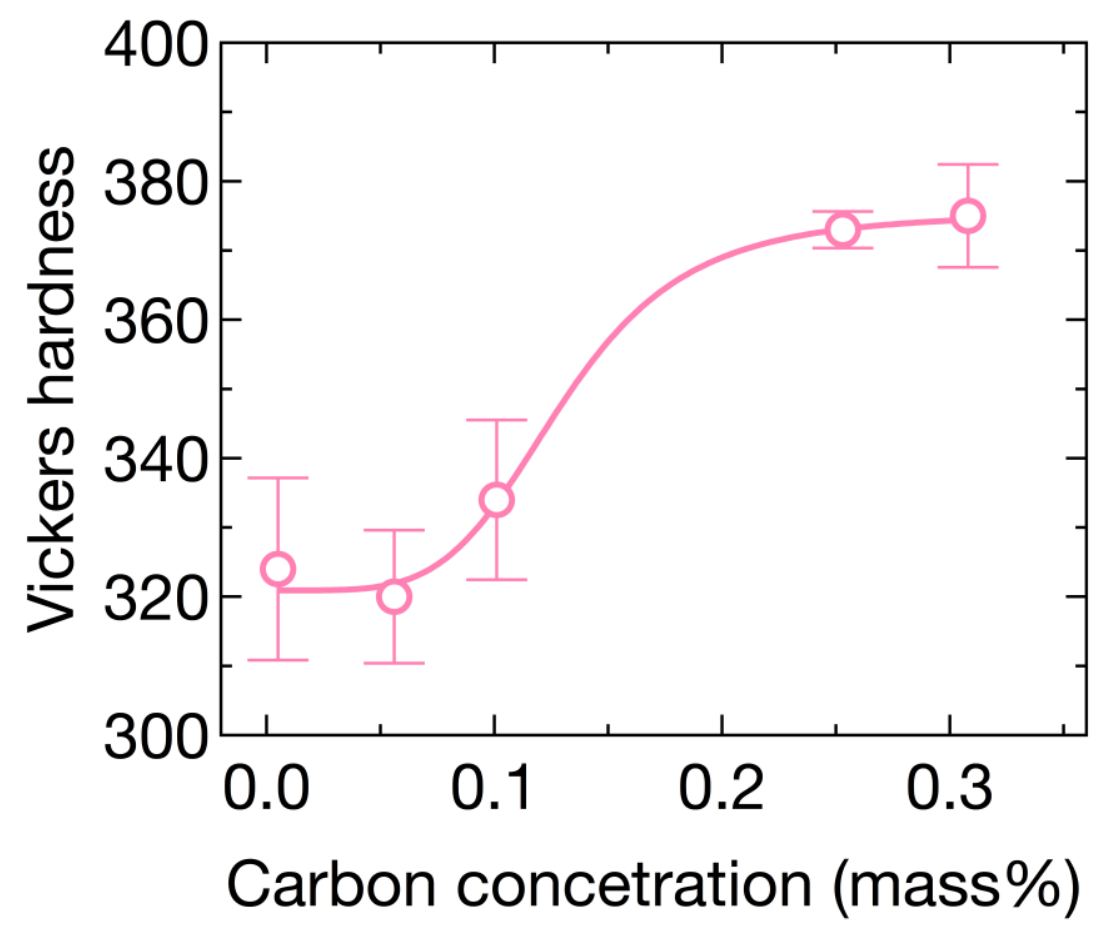

Figure 8 


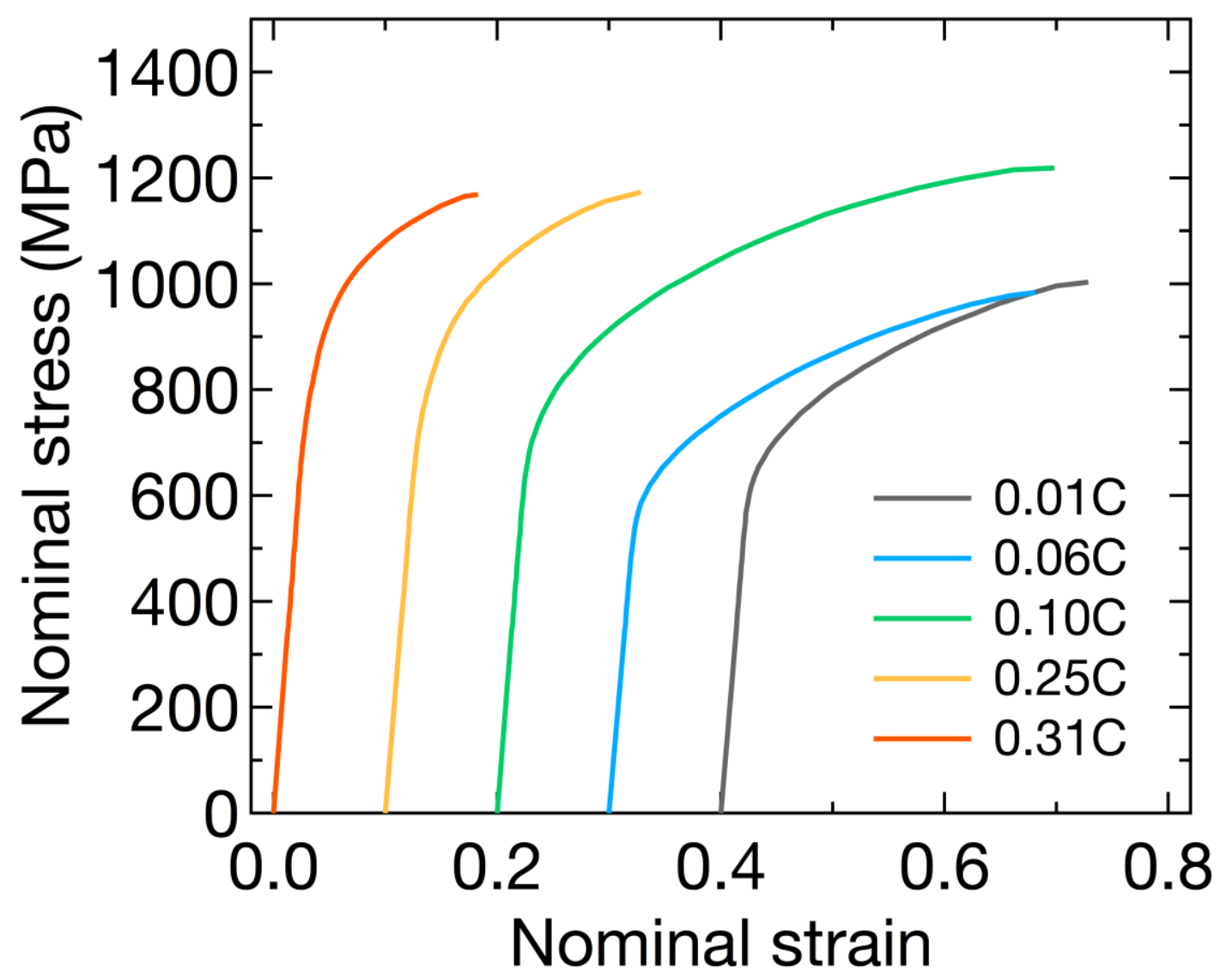

Figure 9 

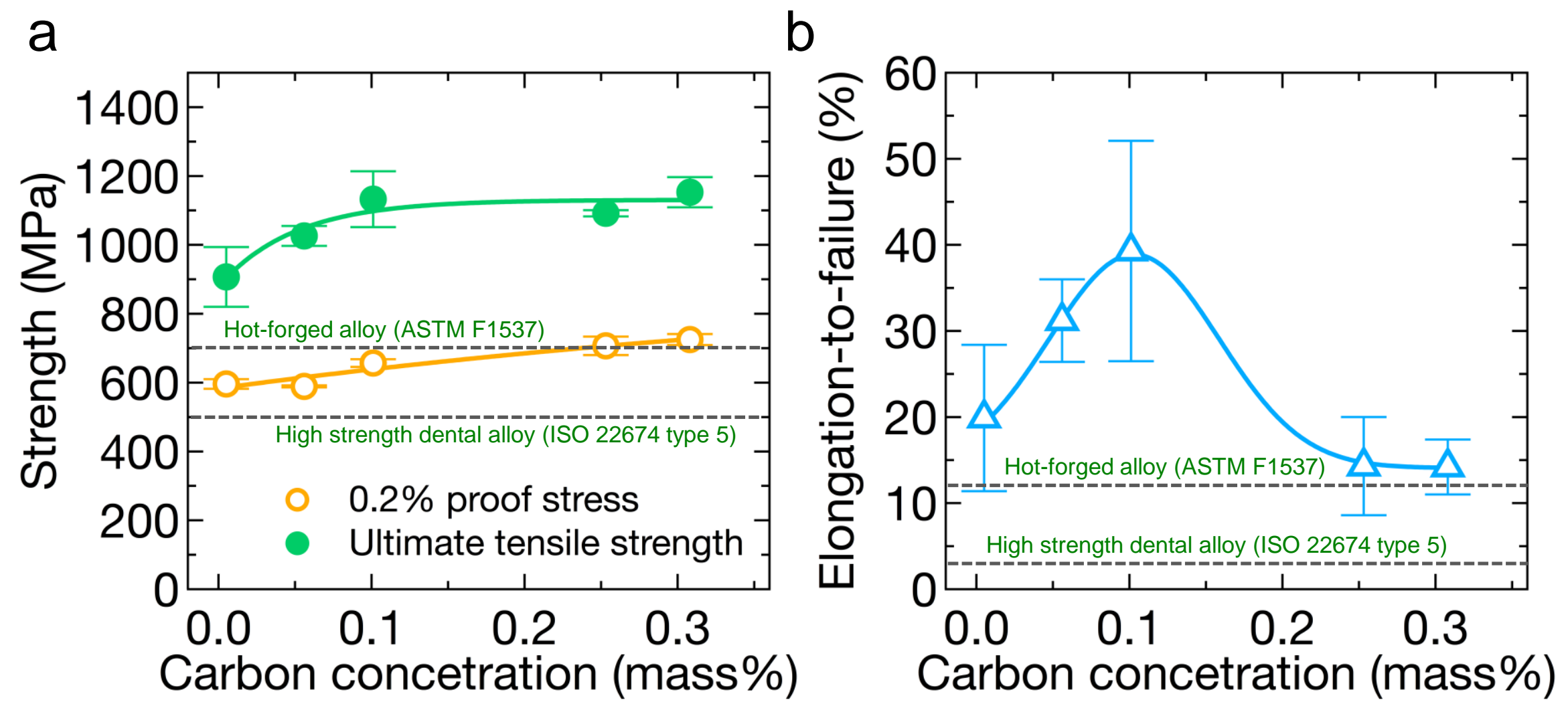

Figure 10 


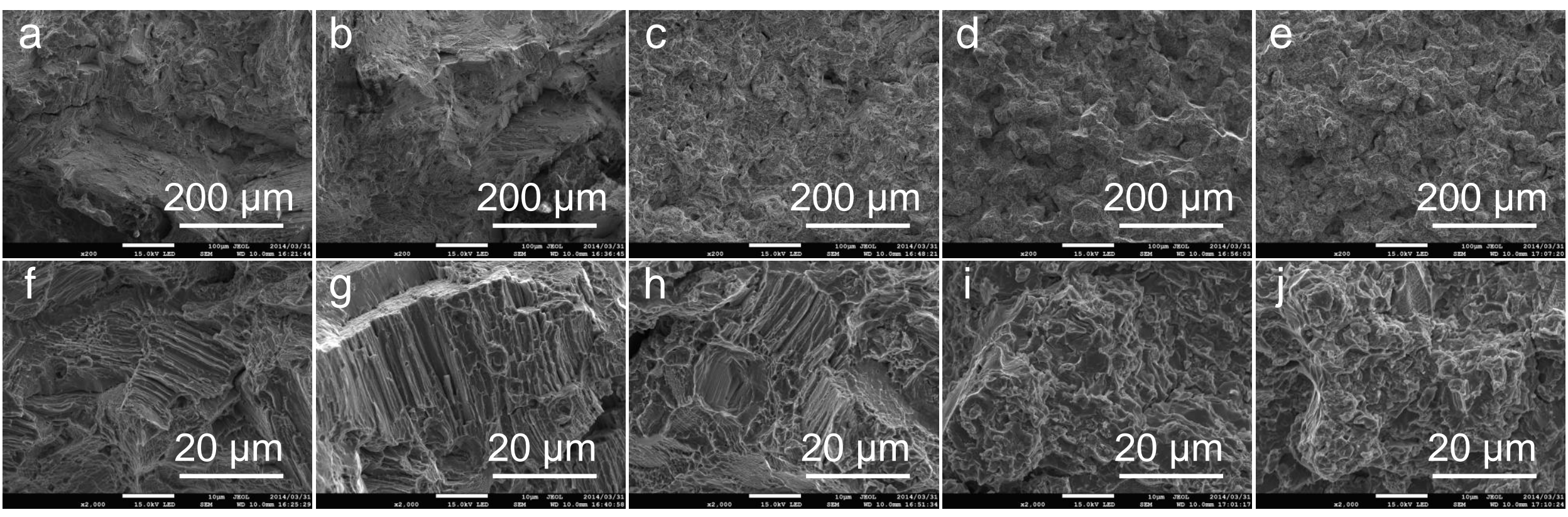

Figure 11 
Cobalt

Other elements: under detection limit

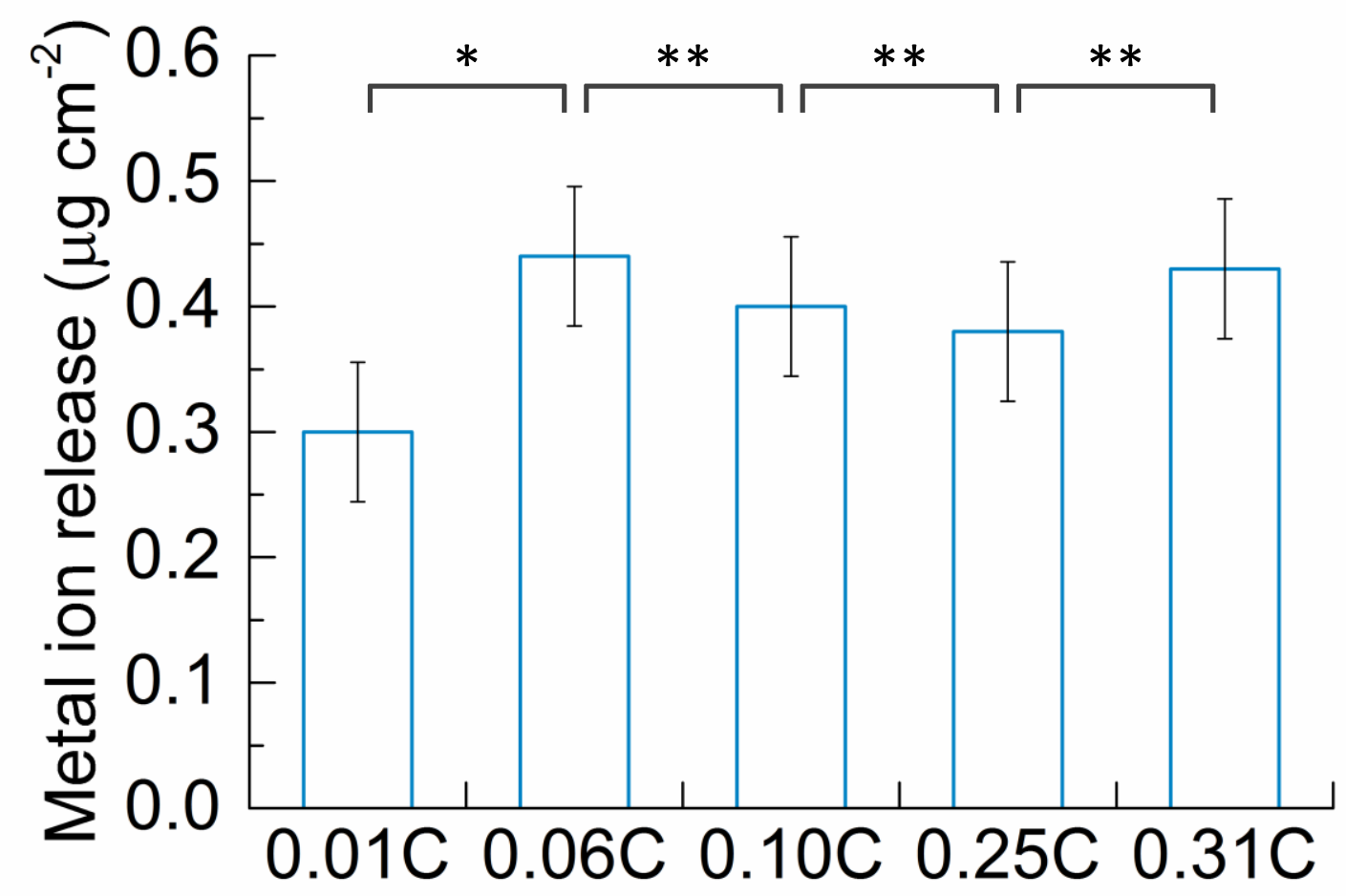

Figure 12 

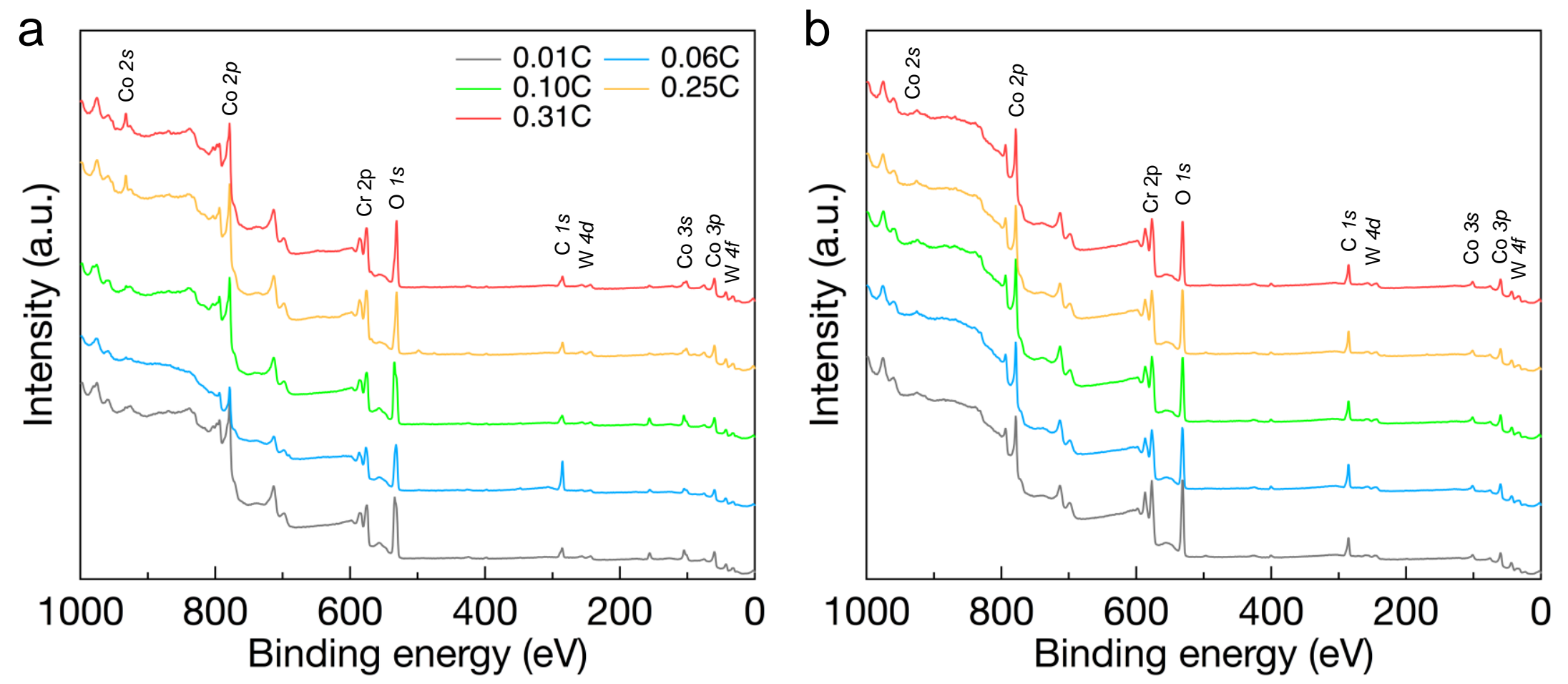

Figure 13 


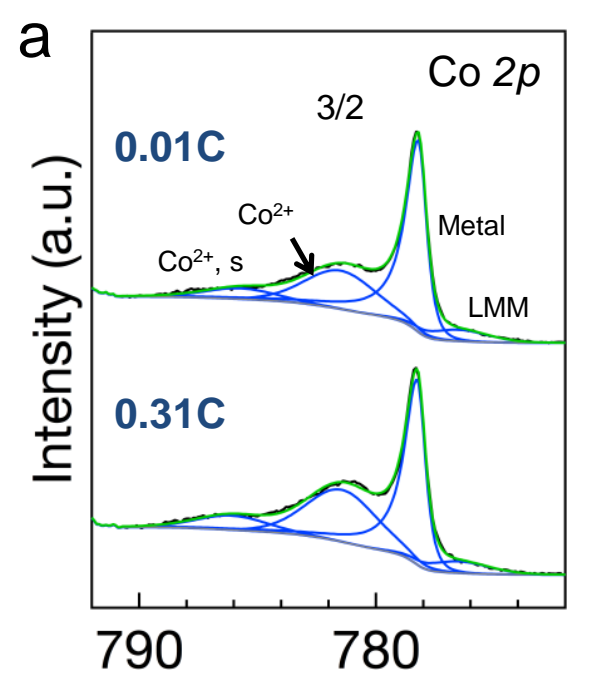

Binding energy (eV)

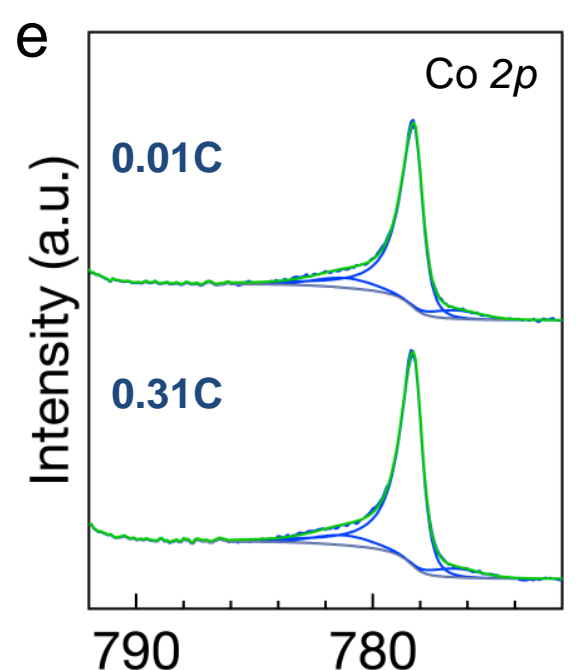

Binding energy (eV)

Figure 14
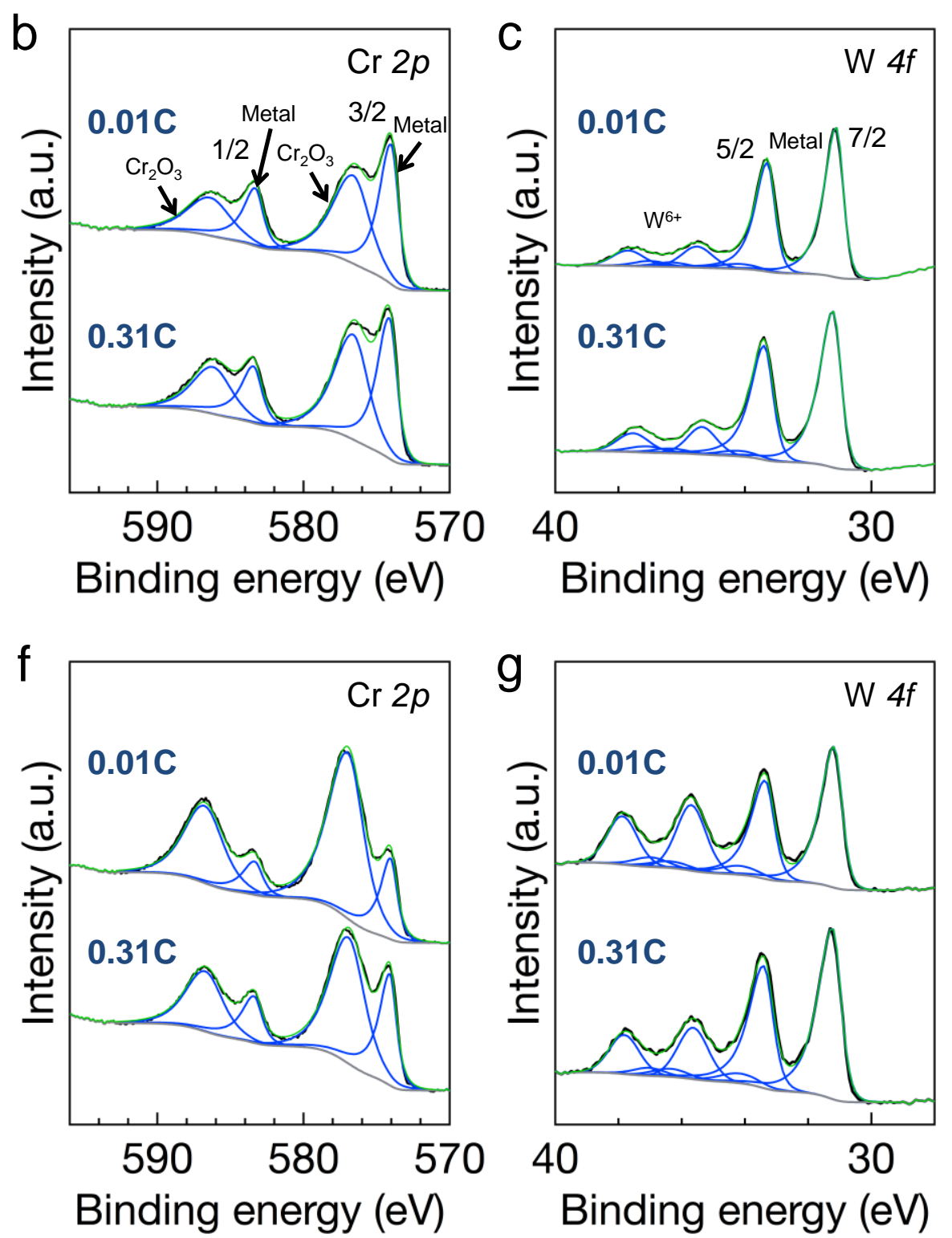

Binding energy (eV)

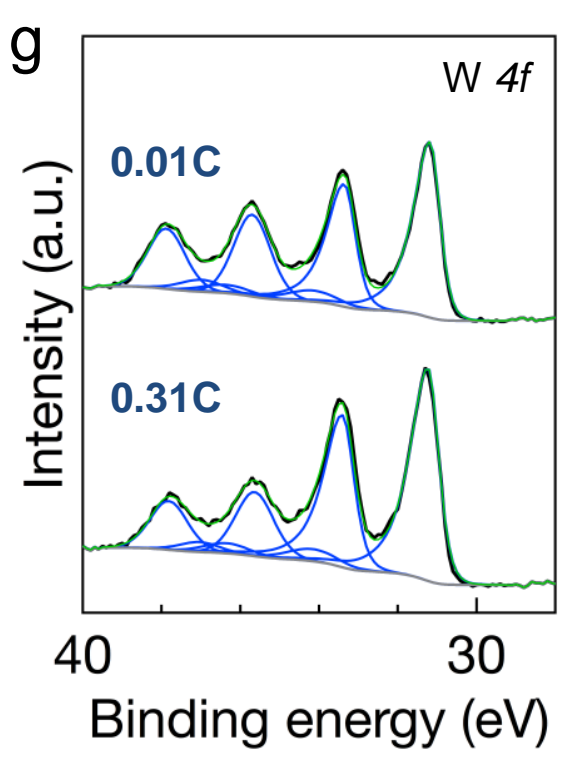

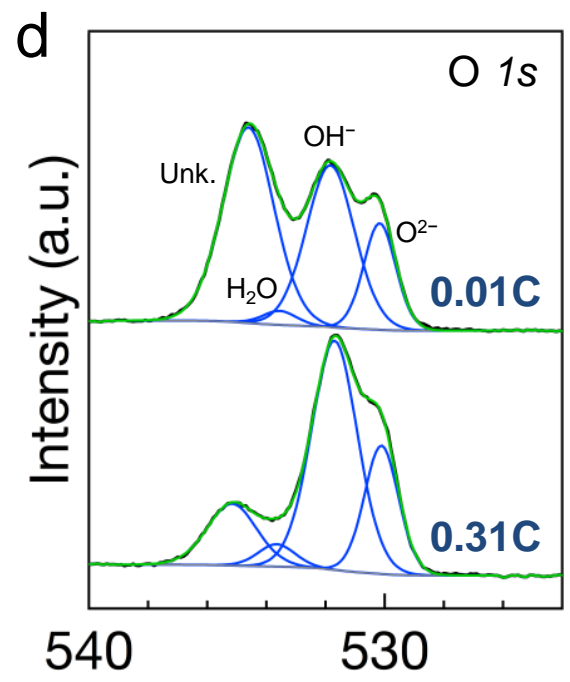

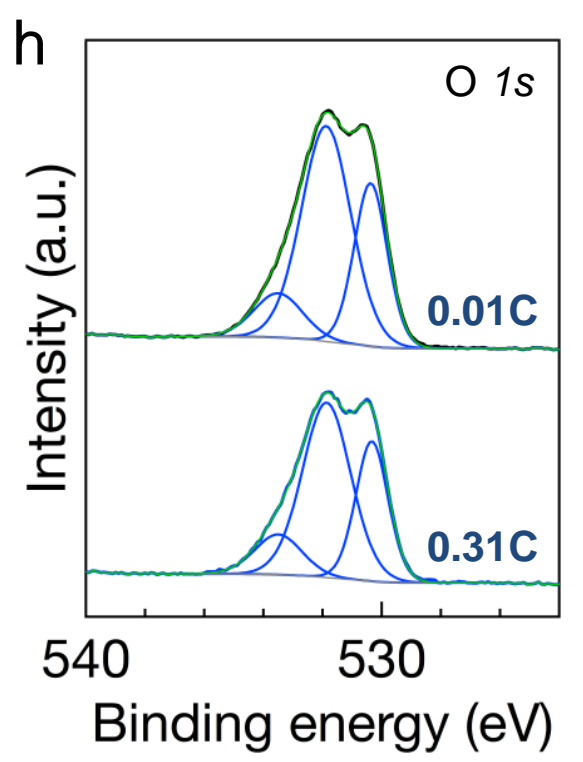



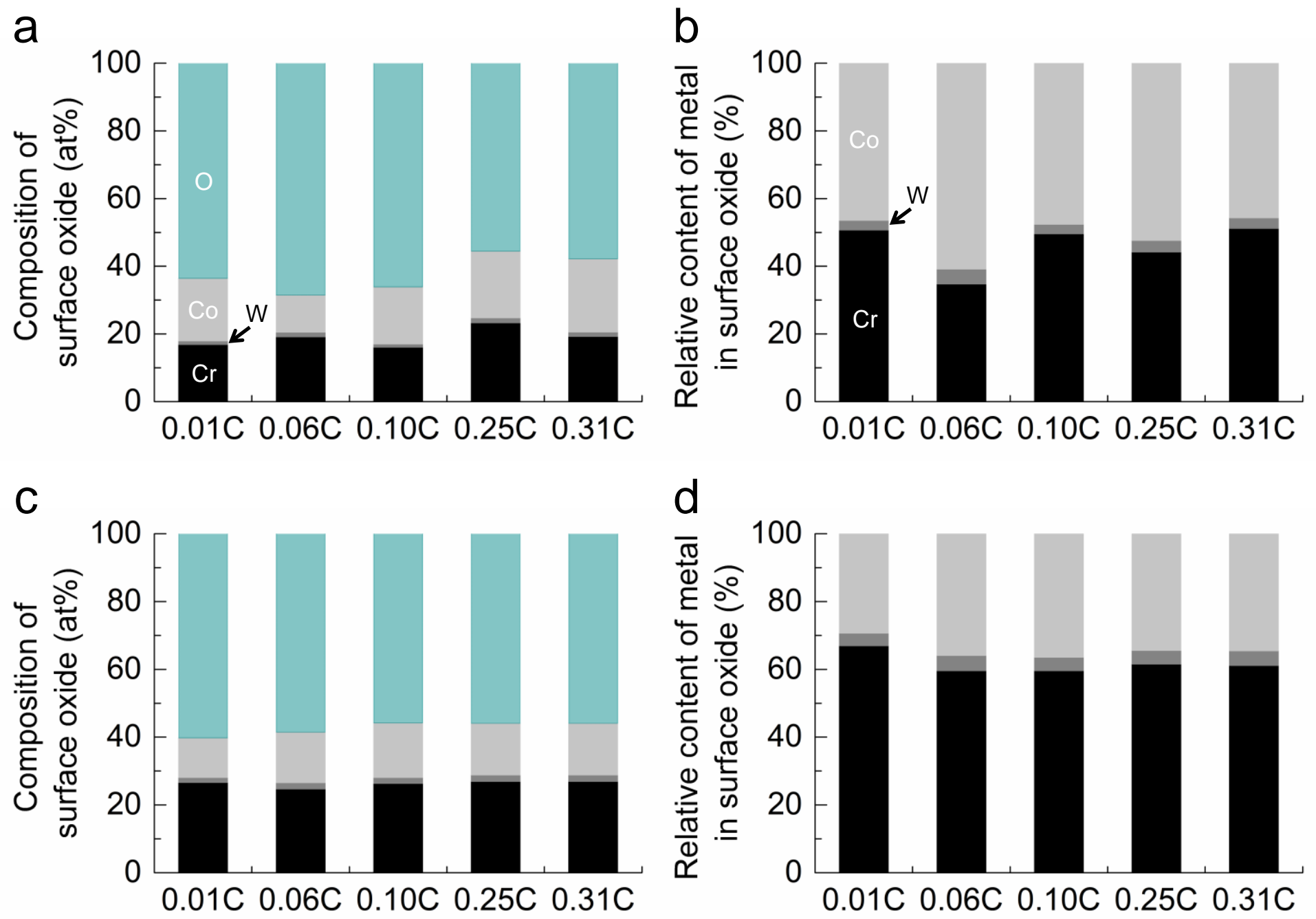

Figure 15 


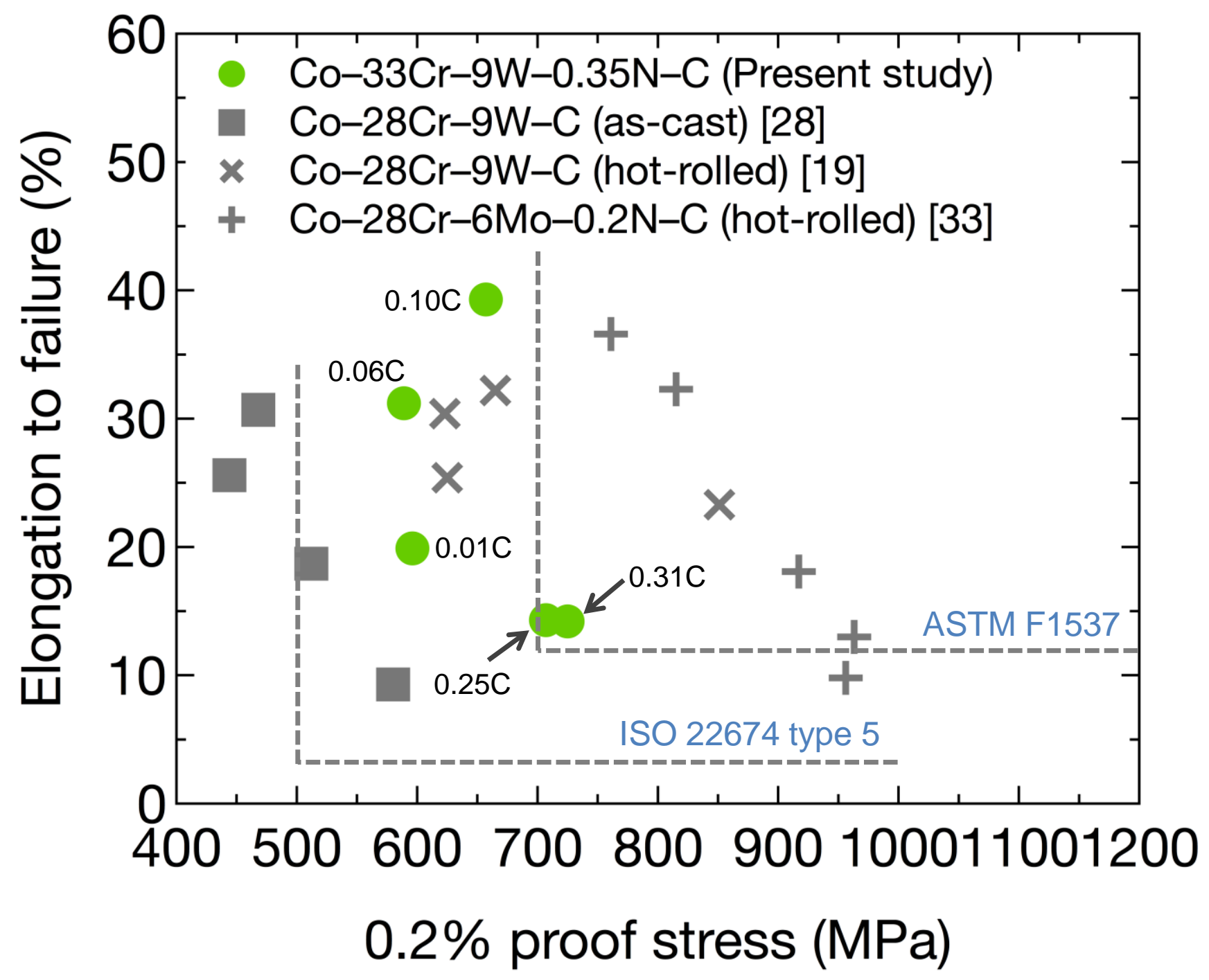

Figure 16 
Table 1

\begin{tabular}{llllllll}
\hline Alloy & Co & Cr & W & Si & C & $\mathrm{N}$ & $\mathrm{O}$ \\
\hline $0.01 \mathrm{C}$ & Bal. & 31.60 & 8.44 & $<0.01$ & 0.005 & 0.336 & 0.017 \\
$0.06 \mathrm{C}$ & Bal. & 32.95 & 9.35 & $<0.01$ & 0.056 & 0.367 & 0.018 \\
$0.10 \mathrm{C}$ & Bal. & 32.95 & 8.71 & $<0.01$ & 0.101 & 0.366 & 0.020 \\
$0.25 \mathrm{C}$ & Bal. & 31.95 & 9.13 & $<0.01$ & 0.253 & 0.368 & 0.018 \\
$0.31 \mathrm{C}$ & Bal. & 32.35 & 9.18 & $<0.01$ & 0.308 & 0.312 & 0.019 \\
\hline
\end{tabular}




\section{Table 2}

\begin{tabular}{llccl}
\hline Alloy & Co & Cr & W & C \\
\hline $0.01 C$ & $43.34 \pm 0.48$ & $50.07 \pm 0.11$ & $5.80 \pm 0.18$ & $0.77 \pm 0.20$ \\
$0.31 C$ & $33.50 \pm 0.76$ & $52.85 \pm 0.25$ & $5.80 \pm 0.06$ & $7.81 \pm 0.49$ \\
\hline
\end{tabular}


Table 3

\begin{tabular}{lllll}
\hline Alloy & $\begin{array}{l}0.2 \% \text { proof stress } \\
(\mathrm{MPa})\end{array}$ & $\begin{array}{l}\text { Ultimate tensile } \\
\text { strength (MPa) }\end{array}$ & $\begin{array}{l}\text { Elongation-to- } \\
\text { failure (\%) }\end{array}$ & Reference \\
\hline $0.01 \mathrm{C}$ & $596 \pm 14$ & $907 \pm 87$ & $19.9 \pm 8.5$ & \\
$0.06 \mathrm{C}$ & $589 \pm 3$ & $1026 \pm 29$ & $31.2 \pm 4.8$ & Present \\
$0.10 \mathrm{C}$ & $657 \pm 11$ & $1133 \pm 81$ & $39.3 \pm 12.8$ & study \\
$0.25 \mathrm{C}$ & $707 \pm 27$ & $1092 \pm 87$ & $14.3 \pm 5.7$ & \\
$0.31 \mathrm{C}$ & $725 \pm 16$ & $1153 \pm 44$ & $14.2 \pm 3.2$ & \\
\hline $0.01 \mathrm{C}$ & $226 \pm 49$ & $842 \pm 19$ & $25.7 \pm 3.4$ & \\
$0.04 \mathrm{C}$ & $444 \pm 5$ & $960 \pm 10$ & $25.6 \pm 2.7$ & \\
$0.10 \mathrm{C}$ & $468 \pm 13$ & $1024 \pm 15$ & $30.7 \pm 2.2$ & {$[28]$} \\
$0.17 \mathrm{C}$ & $512 \pm 39$ & $854 \pm 23$ & $18.7 \pm 0.7$ & \\
$0.27 \mathrm{C}$ & $580 \pm 30$ & $853 \pm 59$ & $9.3 \pm 3.3$ & \\
\hline
\end{tabular}




\section{Table 4}

\begin{tabular}{cccc}
\hline Element & $D_{0}\left(\mathrm{~m}^{2} \mathrm{~s}^{-1}\right)$ & $Q\left(\mathrm{~kJ} \mathrm{~mol}^{-1}\right)$ & Reference \\
\hline Co & $2.3 \times 10^{-5}$ & 268 & {$[32]$} \\
Cr & $8.4 \times 10^{-6}$ & 254 & {$[32]$} \\
W & $8.0 \times 10^{-7}$ & 238 & {$[32]$} \\
C & $2.1 \times 10^{-5}$ & 145 & {$[32]$} \\
\hline
\end{tabular}

$D=D_{0} \exp \left(\frac{Q}{R T}\right)$

$D$ the diffusion coefficient

$D_{0}$ the pre-factor, $Q$ an activation energy,

$R$ the gas constant and $T$ the absolute temperature. 
Table 5

\begin{tabular}{|c|c|c|}
\hline Carbon concentration & $\begin{array}{l}\text { Low-carbon alloys } \\
(0.01-0.10 \text { mass } \%)\end{array}$ & $\begin{array}{l}\text { High-carbon alloys } \\
(0.10-0.31 \text { mass } \%) \\
\end{array}$ \\
\hline Microstructures & $\begin{array}{l}\text { Refinement of solidification } \\
\text { microstructures occurs due } \\
\text { to interdendritic segregation. } \\
\text { - Few interdendritic } \\
\text { precipitates were observed. }\end{array}$ & $\begin{array}{l}\text { - Grain size does not change } \\
\text { with increasing carbon } \\
\text { concentration. } \\
\text { A fraction of intergranular } \\
\text { carbide precipitation } \\
\text { increased with increasing } \\
\text { carbon concentration. }\end{array}$ \\
\hline Tensile properties & $\begin{array}{l}\text { Grain refinement should be } \\
\text { the strengthening } \\
\text { mechanism. } \\
\text { Tensile ductility increased } \\
\text { with an increase in carbon } \\
\text { content. }\end{array}$ & $\begin{array}{l}\text { - Precipitation of carbide } \\
\text { phase contributes to the } \\
\text { strength. } \\
\text { Tensile ductility decreased } \\
\text { due to interdendritic carbide } \\
\text { precipitation. }\end{array}$ \\
\hline $\begin{array}{l}\text { Corrosion properties } \\
\text { (metal ion release) }\end{array}$ & \multicolumn{2}{|c|}{$\begin{array}{l}\text { The corrosion properties of the developed alloys are } \\
\text { basically good compared with conventional Co-Cr alloys. } \\
\text { Small amount of carbon slightly increases the amount of } \\
\text { cobalt released into a solution. } \\
\text { - However, no significant differences in corrosion resistance } \\
\text { and surface chemistry were identified between the alloys. }\end{array}$} \\
\hline
\end{tabular}



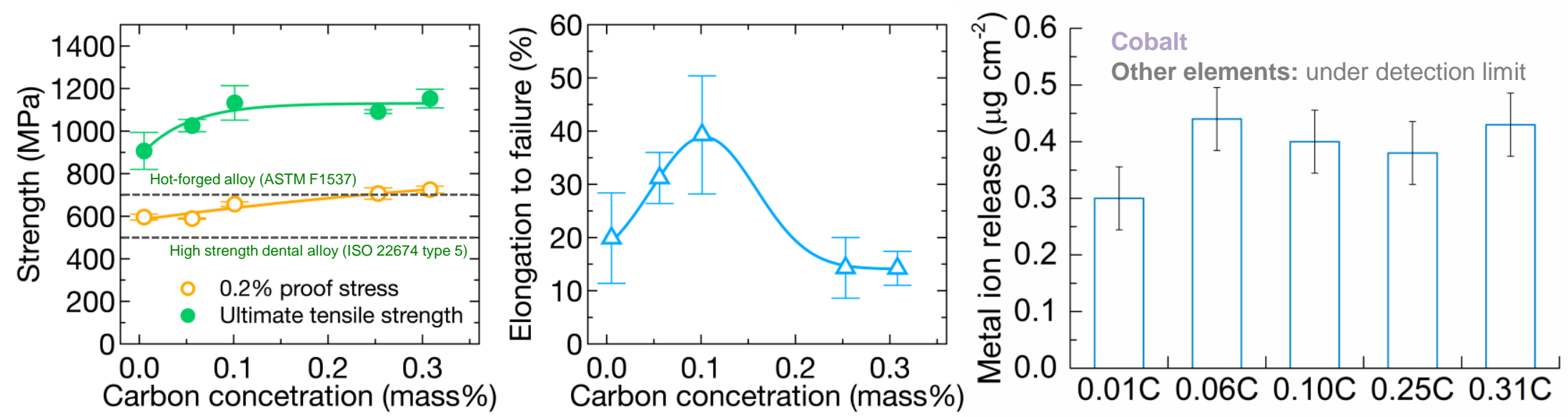